\title{
Inter-laboratory comparison of oxygen isotope compositions from biogenic silica
}

\author{
Bernhard Chapligin $^{\mathrm{a}, *}$, Melanie J. Leng ${ }^{\mathrm{b}}$, Elizabeth Webb ${ }^{\mathrm{c}}$, Anne Alexandre ${ }^{\mathrm{d}}$, \\ Justin P. Dodd ${ }^{\mathrm{e}}$, Akira Ijiri ${ }^{\mathrm{f}}$, Andreas Lücke ${ }^{\mathrm{g}}$, Aldo Shemesh ${ }^{\mathrm{h}}$, \\ Andrea Abelmann ${ }^{\mathrm{a}}$, Ulrike Herzschuh ${ }^{\mathrm{a}}$, Fred J. Longstaffe ${ }^{\mathrm{c}}$, \\ Hanno Meyer ${ }^{\mathrm{a}}$, Robert Moschen ${ }^{\mathrm{g}}$, Yusuke Okazaki ${ }^{\mathrm{f}}$, Nicholas H. Rees ${ }^{\mathrm{i}}$, \\ Zachary D. Sharp ${ }^{\mathrm{e}}$, Hilary J. Sloane ${ }^{\mathrm{b}}$, Corinne Sonzogni ${ }^{\mathrm{d}}$, \\ George E.A. Swann ${ }^{j}$, Florence Sylvestre ${ }^{\mathrm{d}}$, Jonathan J. Tyler ${ }^{\mathrm{k}}$, Ruth Yam ${ }^{\mathrm{h}}$ \\ a Alfred Wegener Institute (AWI) for Polar and Marine Research, Research Unit Potsdam and Bremerhaven, \\ Telegrafenberg A43, D-14473 Potsdam, Germany \\ ${ }^{\mathrm{b}}$ NERC Isotope Geosciences Laboratory (NIGL), British Geological Survey, Keyworth, Nottingham NG12 5GG, UK \\ ${ }^{\mathrm{c}}$ Laboratory for Stable Isotope Science, Department of Earth Sciences, The University of Western Ontario (UWO), \\ London, Ontario, Canada N6A $5 B 7$ \\ ${ }^{\mathrm{d}}$ CEREGE, CNRS, IRD, Université Aix-Marseille, Europôle de l'Arbois, BP 80, 13545 Aix-en-Provence Cedex 4, France \\ ${ }^{\mathrm{e}}$ Department of Earth and Planetary Sciences, Northrop Hall, University of New Mexico (UNM), Albuquerque, NM 87131, USA \\ ${ }^{\mathrm{f}}$ Japan Agency for Marine-Earth Science and Technology (JAMSTEC), 2-15 Natsushima-cho, Yokosuka 237-0061, Japan \\ ${ }^{\mathrm{g}}$ Institute of Bio- and Geosciences, IBG-3: Agrosphere, Research Centre Jülich, D-52425 Jülich, Germany \\ ${ }^{\mathrm{h}}$ Weizmann Institute of Science (WIS), Rehovot 76100, Israel \\ ${ }^{\mathrm{i}}$ Inorganic Chemistry Laboratory, University of Oxford, South Parks Road, Oxford OX1 3QR, UK \\ ${ }^{\mathrm{j}}$ School of Geography, University of Nottingham, University Park, Nottingham NG7 2RD, UK \\ ${ }^{\mathrm{k}}$ Department of Earth Sciences, University of Oxford, South Parks Road, Oxford OX1 3AN, UK
}

Received 14 February 2011; accepted in revised form 7 August 2011; available online 16 August 2011

\begin{abstract}
Several techniques have been introduced in the last decades for the dehydration and release of $\mathrm{O}_{2}$ from biogenic silica (opal-A) for oxygen-isotope analysis. However, only one silica standard is universally available: a quartz standard (NBS28) distributed by the IAEA, Vienna. Hence, there is a need for biogenic silica working standards. This paper compares the existing methods of oxygen-isotope analyses of opal-A and aims to characterize additional possible working standards to calibrate the $\delta^{18} \mathrm{O}$ values of biogenic silica. For this purpose, an inter-laboratory comparison was organized. Six potential working standard materials were analysed repeatedly against NBS28 by eight participating laboratories using their specific analytical methods. The materials cover a wide range of $\delta^{18} \mathrm{O}$ values $(+23$ to $+43 \%$ ) and include diatoms (marine, lacustrine), phytoliths and synthetically-produced hydrous silica. To characterize the proposed standards, chemical analyses and imaging by scanning electron microscopy (SEM) were also performed. Despite procedural differences at each laboratory, all methods are in reasonable agreement with a standard deviation (SD) for $\delta^{18} \mathrm{O}$ values between $0.3 \%$ and $0.9 \%$ o $(1 \sigma)$. Based on the results, we propose four additional biogenic silica working standards (PS1772-8: 42.8\%; BFC: 29.0\%; MSG60: 37.0\%; G95-25-CL leaves: $36.6 \%$ ) for $\delta^{18} \mathrm{O}$ analyses, available on request through the relevant laboratories.
\end{abstract}

(C) 2011 Elsevier Ltd. All rights reserved.

\footnotetext{
* Corresponding author. Tel.: +49331288 2152; fax: +49331288 2137.

E-mail address: bernhard.chapligin@awi.de (B. Chapligin).
} 


\section{INTRODUCTION}

The oxygen-isotope composition $\left(\delta^{18} \mathrm{O}\right.$ value $)$ of biogenic silica is widely used as a proxy indicator for paleoclimate reconstruction from marine (Matheney and Knauth, 1989; Shemesh et al., 1992; Swann et al., 2008) and lacustrine (Shemesh and Peteet, 1998; Rosqvist et al., 1999; Shemesh et al., 2001; Leng and Marshall, 2004; Mackay et al., 2008; Tyler et al., 2008) records. Modern, terrestrial (Shahack-Gross et al., 1996; Webb and Longstaffe, 2000; Webb and Longstaffe, 2002; Hodson et al., 2008) (phytolith) records underline the potential of $\delta^{18} \mathrm{O}$ in biogenic silica for climatic reconstruction. The number of studies using this technique has increased in the last decade and the discipline has been recently reviewed (Leng and Barker, 2006; Swann and Leng, 2009). Significant advances have been made in the cleaning of sediment samples (Morley et al., 2004; Rings et al., 2004; Swann et al., 2006; Crespin et al., 2008) and in the ability to quantify and correct for residual contamination (Lamb et al., 2007; Brewer et al., 2008; Swann and Patwardhan, 2011). Perhaps the greatest remaining analytical issue concerns removal (or the controlled isotopic exchange and then removal = "fixing") of the exchangeable oxygen contained in hydrous groups during oxygen isotope analyses of biogenic silica. Biogenic silica has an amorphous structure containing $\mathrm{Si}-\mathrm{O}-\mathrm{Si}$ bonds, $\mathrm{Si}-\mathrm{OH}$ bonds and crystallization water (Knauth and Epstein, 1982). These oxygen-bearing compounds $\left(-\mathrm{OH}\right.$ and $\left.\mathrm{H}_{2} \mathrm{O}\right)$ can exchange freely with the environment, for example with porewater during burial of diatoms (Mopper and Garlick, 1971; Kawabe, 1978; Mikkelsen et al., 1978; Schmidt et al., 1997; Brandriss et al., 1998; Moschen et al., 2006). Removal or fixing of the exchangeable oxygen prior to oxygen-isotope analysis is therefore crucial since all methods fully react the sample and the $\delta^{18} \mathrm{O}$ values reflect all of the liberated oxygen.

To date, four methods have been established to compensate for the exchangeable oxygen and have been utilized by one or more of the eight laboratories participating in this study (Table 1): Labeyrie (1974) and Labeyrie and Juillet (1982) first introduced (1) the controlled isotopic exchange (CIE) method. Here, any loosely-bound oxygen is exchanged with oxygen from water vapour in equilibrium with labelled waters of known higher and lower ${ }^{18} \mathrm{O} /{ }^{16} \mathrm{O}$ compared to the biogenic silica. The exchanged samples are then sintered at more than $1000{ }^{\circ} \mathrm{C}$ under high vacuum for $6-18 \mathrm{~h}$, to crystallize the silica. Sintered samples are then reacted with a fluorinating reagent such as $\mathrm{F}_{2}, \mathrm{ClF}_{3}$ or $\mathrm{BrF}_{5}$ to liberate molecular oxygen in the silica and collect it for mass spectrometry. A mass balance calculation is used to obtain the percentage of exchanged oxygen and the resulting oxygen-isotope composition of the sample, taking into account the isotopic fractionations between water and water vapour $\left(\Delta_{\text {water-vapour }}\right)$ and between vapour and the final exchanged oxygen $\left(\Delta_{\text {vapour-Oexchanged }}\right)$. Other laboratories have adapted, modified and improved this method (Shemesh et al., 1992; Webb and Longstaffe, 2000; Crespin et al., 2008).

In the early 1980s, Haimson and Knauth (1983) introduced (2) the stepwise fluorination (SWF) method in which the biogenic material is heated and partially reacted with a fluorinating reagent. Oxygen atoms from $\mathrm{Si}-\mathrm{OH}$ bonds react at lower temperatures because of their lower bond-energy and thus, are removed first. Once weakly bound oxygen is released, the sample is again reacted with a fluorinating reagent at a higher temperature and a plateau of the $\delta^{18} \mathrm{O}$ values is reached that reflects climate-relevant $\delta^{18} \mathrm{O}$ values from the remaining structural oxygen. The

Table 1

Participating laboratories, and methods used by each laboratory to remove or exchange the hydrous layer and liberate oxygen from the structural silica.

\begin{tabular}{|c|c|c|c|c|c|}
\hline Laboratory & Authors & $\begin{array}{l}\text { "Si-OH" } \\
\text { removal }^{\mathrm{a}}\end{array}$ & Periphery & Mass Spectrometer & References \\
\hline $\begin{array}{l}\text { AWI } \\
\text { Germany }\end{array}$ & $\begin{array}{l}\text { B. Chapligin, H. Meyer, } \\
\text { U. Herzschuh, A. Abelmann }\end{array}$ & iGFD & $\begin{array}{l}\text { Laser-Fluorination, } \\
\mathrm{BrF}_{5}\end{array}$ & PDZ Europa 20-20 & Chapligin et al. (2010) \\
\hline $\begin{array}{l}\text { NERC } \\
\text { UK }\end{array}$ & $\begin{array}{l}\text { M. Leng, H. Sloane, G. } \\
\text { Swann, }\end{array}$ & $\begin{array}{l}\text { SWF w/ } \\
\mathrm{BrF}_{5}\end{array}$ & Conventional, $\mathrm{BrF}_{5}$ & Finnigan MAT-253 & Leng et al. (2001) \\
\hline $\begin{array}{l}\text { UNM } \\
\text { USA }\end{array}$ & J. Dodd, Z. Sharp & $\mathrm{SWF} w / \mathrm{F}_{2}$ & $\begin{array}{l}\text { Laser-Fluorination, } \\
\mathrm{BrF}_{5}\end{array}$ & $\mathrm{TF}^{\mathrm{b}}$ Delta Plus & Dodd and Sharp (2010) \\
\hline $\begin{array}{l}\text { UWO } \\
\text { Canada }\end{array}$ & E. Webb, F. Longstaffe & CIE & Conventional, $\mathrm{ClF}_{3}$ & $\mathrm{TF}^{\mathrm{b}}$ Delta Plus & Webb and Longstaffe (2000) \\
\hline $\begin{array}{l}\text { WIS } \\
\text { Israel }\end{array}$ & A. Shemesh & CIE & $\begin{array}{l}\text { Conventional, } \mathrm{BrF}_{5} \\
\text { Laser-Fluorination, } \\
\mathrm{BrF}_{5}\end{array}$ & $\begin{array}{l}\text { Finnigan MAT-250 } \\
\text { TF }^{\mathrm{b}} \text { Delta Plus Adv. }\end{array}$ & Shemesh et al. (1992) \\
\hline $\begin{array}{l}\text { CEREGE } \\
\text { France }\end{array}$ & $\begin{array}{l}\text { A. Alexandre, F. Sylvestre, } \\
\text { C. Sonzogni }\end{array}$ & CIE & $\begin{array}{l}\text { Laser-Fluorination, } \\
\mathrm{BrF}_{5}\end{array}$ & $\mathrm{TF}^{\mathrm{b}}$ Delta Plus & Crespin et al. (2008) \\
\hline $\begin{array}{l}\text { JAMSTEC } \\
\text { Japan }\end{array}$ & A. Ijiri, Y. Okazaki & $\begin{array}{l}\text { iHTR } \\
\text { pre-heating }\end{array}$ & iHTR & $\mathrm{TF}^{\mathrm{b}}$ Delta Plus & \\
\hline $\begin{array}{l}\text { FZJ } \\
\text { Germany }\end{array}$ & A. Lücke, R. Moschen & $\begin{array}{l}\text { iHTR } \\
\text { pre-heating }\end{array}$ & iHTR & $\begin{array}{l}\mathrm{TF}^{\mathrm{b}} \text { Delta } \\
\text { Advantage }\end{array}$ & Lücke et al. (2005) \\
\hline
\end{tabular}

${ }^{\mathrm{a}} \mathrm{HFD}=$ Helium flow dehydration; $\mathrm{CIE}=$ Controlled isotopic exchange; $\mathrm{SWF}=$ stepwise fluorination; iHTR $=$ inductive high temperature carbon reduction.

${ }^{\mathrm{b}} \mathrm{TF}=$ Thermo Finnigan. 
method was later adopted and refined by Sharp (1990, 1992), Vennemann et al. (2002) and Leng and Sloane (2008).

Two additional methods for removing the hydrous layer without isotopic fractionation have been established more recently: Lücke et al. (2005) use (3) inductive high-temperature carbon reduction (iHTR) in which silica is reduced on a hot glassy-carbon rod to carbon monoxide (CO) at temperatures of $>1550{ }^{\circ} \mathrm{C}$ after progressive, thermally-excited dehydration (up to $1000{ }^{\circ} \mathrm{C}$ ) under high vacuum. Dehydration and reduction is performed consecutively in the same reaction chamber without sample transfer.

The fourth method (4) involves vacuum dehydration. Labeyrie (1974) and Mopper and Garlick (1971) first applied this approach in the early 1970 s by heating the samples to $1050{ }^{\circ} \mathrm{C}$ under vacuum, but not all exchangeable oxygen was removed. This method was recently improved by using (4) inert gas flow dehydration (iGFD) during which exchangeable oxygen is removed at $1100{ }^{\circ} \mathrm{C}$ under a continuous flow of helium (Chapligin et al., 2010).

Generally, after the removal or fixing of exchangeable oxygen by the various methods the stable oxygen from the $\mathrm{Si}-\mathrm{O}-\mathrm{Si}$ structure is liberated either by conventional (slow reaction in heated nickel cylinders) or laser (fast reac-

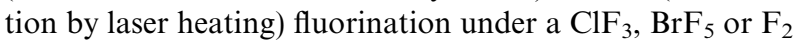
atmosphere. The oxygen is then reduced quantitatively to $\mathrm{CO}_{2}$ for oxygen isotope analysis or analysed directly as $\mathrm{O}_{2}$ in the mass spectrometer. Alternatively, Lücke et al. (2005) reduce the oxygen to $\mathrm{CO}$ over graphite as described earlier.

There is no commercially available "off the shelf" instrumentation that is suitable for biogenic silica dehydration and liberation of free $\mathrm{O}_{2}$ for oxygen-isotope analysis. So, even laboratories using the same method have a different, custom-built instrumentation that apart from the method differences themselves creates a serious need for this comparative study. Inter-laboratory comparisons of biogenic opal-A measurements such as the percentage of biogenic silica in sediments ( $\mathrm{BSi}(\%))$ and $\delta^{30} \mathrm{Si}$ values in biogenic silica have been performed in the last decades (Conley, 1998; Reynolds et al., 2007). For the determination of $\delta^{18} \mathrm{O}$ values of biogenic silica only one intra-laboratory comparison between two analytical methods (CIE, SWF) has been performed previously (Schmidt et al., 1997). Both CIE and
SWF produced reliable results in that test when comparing three samples $\left(\Delta^{18} \mathrm{O}=0.1-0.2 \%\right.$, no $n$ provided $)$, although in one instance a differences in $\delta^{18} \mathrm{O}$ values of up to $3.5 \%$ were observed for a single sample. The main aims of this inter-laboratory comparison are:

- To test if the same (or similar) analytical methods applied in different laboratories provide reproducible $\delta^{18} \mathrm{O}$ values (method performance study).

- To test if the four different methods compensating for the exchangeable oxygen used in eight different laboratories result in accurate and reproducible $\delta^{18} \mathrm{O}$ values (proficiency study).

- To establish new biogenic silica working standards covering a large range of $\delta^{18} \mathrm{O}$ values that can be distributed within the scientific community (material certification study).

\section{MATERIALS AND METHODS}

\subsection{Materials}

One goal of the comparison was to establish biogenic silica working standards with a high reproducibility covering a large range of $\delta^{18} \mathrm{O}$ values. Currently, there is just one certified quartz standard available: NBS28 which has a defined value of $\delta^{18} \mathrm{O}=+9.57 \%$ (Hut, 1987; Gröning et al., 2007). It provides a calibration point in this study for evaluating the precision and accuracy of oxygen-isotope analyses of anhydrous silica. The standard deviation for NBS28 in all laboratories but JAMSTEC ranged between 0.1 and $0.2 \%$ $(1 \sigma)$, for JAMSTEC the standard deviation was $0.36 \%$ $(1 \sigma, n=24)$. However, NBS28 is not sufficient as a reference material for biogenic silica, since (1) its $\delta^{18} \mathrm{O}$ value is much lower than that of most biogenic opal which could cause errors in case of non-linearities of the instrument, and (2) it cannot be used to test the reproducibility of direct dehydration or CIE processes. To fill this void, six biogenic silica samples (Table 2, all except NFC have so far been used as internal laboratory standards and thus are referred to as working standards in the following text) were chosen, provided to AWI, split into aliquots and distributed to the participating laboratories.

Table 2

Type, origin and references for the working standards.

\begin{tabular}{|c|c|c|c|c|c|c|}
\hline Supplier & Name & Abb. & Type & Description & Location & References \\
\hline AWI & PS1772-8 & PS & Diatom & Marine sediment & $\begin{array}{l}\text { Southern Ocean, } \\
\text { Atlantic Ridge }\end{array}$ & $\begin{array}{l}\text { Gersonde and Hempel (1990) and } \\
\text { Chapligin et al. (2010) }\end{array}$ \\
\hline NERC & $\mathrm{BFC}$ & $\mathrm{BFC}$ & Diatom & Lacustrine deposit & $\begin{array}{l}\text { Shastra County, } \\
\text { California, USA }\end{array}$ & $\begin{array}{l}\text { Leng et al. (2001) and } \\
\text { Leng and Sloane (2008) }\end{array}$ \\
\hline CEREGE & MSG60 & MSG & Phytolith & Fossil grass phytoliths & $\begin{array}{l}\text { Réunion, France } \\
\text { (Indian Ocean) }\end{array}$ & Crespin et al. (2008) \\
\hline UWO & $\begin{array}{l}\text { G95-25-CL } \\
\text { (leaves) }\end{array}$ & G95 & phytolith & Fresh grass phytoliths & Wyoming, USA & Webb and Longstaffe (2002) \\
\hline FZJ & HT & HT & $\begin{array}{l}\text { Kieselgur } \\
\text { (diatom) }\end{array}$ & $\begin{array}{l}\text { Kieselgur (Merck Product } \\
\text { No. } 1.07910 .1000)\end{array}$ & Unknown & $\begin{array}{l}\text { http://certificates.merck.de and } \\
\text { Lücke et al. (2005) }\end{array}$ \\
\hline NERC & NFC & NFC & Synthetic & $\begin{array}{l}\text { Chemically precipitated } \\
\text { amorphous silica }\end{array}$ & $\begin{array}{l}\text { Synthetised in } \\
\text { laboratory }\end{array}$ & \\
\hline
\end{tabular}


The working standards were selected because of their high degree of purity and oxygen-isotope reproducibility. Cleaning procedures had been used to remove potential contaminants such as carbonates, organics and other mineral phases (Juillet-Leclerc and Labeyrie, 1987; Shemesh et al., 1988; Shemesh et al., 1995; Ellwood and Hunter, 1999; Morley et al., 2004). It is not the aim of this study to assess possible changes in the isotopic composition introduced by these protocols. The working standards were thoroughly mixed. They represent different origins and types (two diatom materials, two phytolith materials, one heated diatomite, one synthetically-precipitated material comprising nano-spheres of hydrated silica), and have a large range of $\delta^{18} \mathrm{O}$ values (approx. +23 to $+43 \%$ ) typical of lacustrine and marine sediment records. Details for each working standard material are provided below.

PS1772-8 originates from a sediment core drilled in 1989 in the Southern Ocean (Lat: -55.4583 , Long: 1.1633, water depth $4.137 \mathrm{~m}$, campaign: ANT-VIII/3) from the R/V Polarstern (Gersonde and Hempel, 1990). The working standard was taken from a homogenous, diatom-rich section of the core (main genera: Fragilariopsis) corresponding to MIS 5e age. For purification PS1772-8 was treated multiple times with a $1: 1$ mixture of $65 \% \mathrm{HClO}_{4}$ and $65 \% \mathrm{HNO}_{3}$ at $60{ }^{\circ} \mathrm{C}$. Recent studies at AWI using the HFD had a longterm reproducibility of $\delta^{18} \mathrm{O}=+43.3 \pm 0.3 \%$ o $(1 \sigma), n=27$ (Chapligin et al., 2010).

BFC is a diatomite from Shastra County California. BFC was cleaned by adding $\mathrm{HCl}(10 \%)$ and $\mathrm{H}_{2} \mathrm{O}_{2}(33 \%)$ at $80{ }^{\circ} \mathrm{C}$ for one hour followed by $60 \% \mathrm{HNO}_{3}$ at $80{ }^{\circ} \mathrm{C}$ for $2 \mathrm{~h}$. Previous studies at NERC using SWF had the long-term reproducibility of $\mathrm{BFC}$ to be $\delta^{18} \mathrm{O}=+28.9 \pm 0.3 \%(n>1000)$. We note that the $\delta^{18} \mathrm{O}$ value given in Leng and Sloane (2008) is $+28.6 \% \pm 0.3 \%$, $n=25$, which was the value over the period of those experiments.

MSG60 consists of grass phytoliths from Mascareignite soil, Reunion Island (Indian Ocean) (Crespin et al., 2008). The dry soil was crushed and sieved at $2 \mathrm{~mm}$. Carbonates were dissolved using $\mathrm{HCl}(1 \mathrm{~N})$, iron oxides reduced with trisodium citrate $\left(\mathrm{C}_{6} \mathrm{H}_{5} \mathrm{Na}_{3} \mathrm{O}_{7}\right)$ and sodium dithionite $\left(\mathrm{Na}_{2} \mathrm{O}_{4} \mathrm{~S}_{2}, \mathrm{H}_{2} \mathrm{O}\right)$ and organic matter oxidised using $\mathrm{H}_{2} \mathrm{O}_{2}$ $(30 \%)$. These steps were performed at $50{ }^{\circ} \mathrm{C}$. The working standard was then sieved at $60 \mu \mathrm{m}$ and phytoliths densimetrically separated using a zinc bromide heavy liquid $\left(\mathrm{ZnBr}_{2}\right)$ with a density of $2.3 \mathrm{~g} \mathrm{~cm}^{-3}$ (Crespin et al., 2008). A previous study at CEREGE suggests that MSG60 has $\delta^{18} \mathrm{O}=$ $+38.4 \pm 0.5 \%, n>37$ using CIE (Crespin et al., 2008).

G95-25-CL leaves is a phytolith working standard extracted from a living grass collected close to Cheyenne, Wyoming (US) (species: Calamovilfa longifolia) (Webb and Longstaffe, 2002). The grasses were air-dried and dissected into different plant tissues. The leaves were washed to remove mineral matter. Plant matter was digested using $\mathrm{H}_{2} \mathrm{SO}_{4}$ and $\mathrm{H}_{2} \mathrm{O}_{2}$. The phytoliths were subsequently freezedried. A previous study (Webb and Longstaffe, 2002) using CIE suggests that G95-25-CL leaves (there called "Cheyenne Wyoming") has $\delta^{18} \mathrm{O}=+36.3 \% \pm 0.1 \%, n=8$.

HT (Kieselgur) is commercially available at MERCK (http://www.merck-chemicals.com). The material was acid-washed and calcinated at $900{ }^{\circ} \mathrm{C}$. Its specifications are listed in the Merck product sheet no. 1.07910.1000. Its first published oxygen-isotope composition - under the name "Opal-1" - is $\delta^{18} \mathrm{O}=+25.6 \pm 0.2 \%, n=6$ (Lücke et al., 2005) and was obtained using iHTR.

NFC is synthetic amorphous silicate material ("Stoeber spheres") produced according to the protocol of Stoeber et al. (1968). This study was the first time this type of material has been analysed for its oxygen isotopic composition.

\subsection{Methods used for assessing standard purity and structure}

Standard purity was evaluated using microscopic, chemical and powder X-ray diffraction methods. Images were obtained using a ZEISS ULTRA 55 Plus Schottky-type field emission scanning electron microscope (FESEM) at the German Research Center for Geoscience, Potsdam.

Chemical compositions ( $\mathrm{Na}, \mathrm{K}, \mathrm{Ca}, \mathrm{Mg}, \mathrm{Mn}, \mathrm{Ti}, \mathrm{P}, \mathrm{S}$, and $\mathrm{Si}$ displayed as oxides) were measured using X-ray fluorescence (XRF) spectrometry at the British Geological Survey (NERC laboratory, Keyworth, UK) (Lamb et al., 2007; Brewer et al., 2008). One gram of each working standard was first subjected to loss on ignition (LOI) for $1 \mathrm{~h}$ at $1050{ }^{\circ} \mathrm{C}$. The working standard was then mixed with approx. $9 \mathrm{~g}$ of Li-tetraborate flux and after fusion the melts were cast into beads. The beads were analysed using an Axios Advanced X-ray spectrometer (Panalytical, Almelo, Netherlands) equipped with a $60 \mathrm{kV}$ generator and $4 \mathrm{~kW}$ rhodium (Super Sharp) end-window X-ray tube. The data were processed using the PANalytical SuperQ XRF software. Results were normalised to $100 \%$ after correction for LOI. To evaluate the source of the LOI (i.e. chemically bound water and/or organic matter) total carbon (TC), total nitrogen (TN) and total sulphur (TS) contents were measured for each working standard using a 'vario EL III'CNS-Elemental Analyzer at AWI.

To test for crystalline contaminants X-ray diffraction (XRD) analyses were performed at the University of Western Ontario (UWO) using a Rikagu Rotaflex RTP-300 rotating Co-anode X-ray diffractometer operated at $45 \mathrm{kV}, 160 \mathrm{~mA}$ and a scan rate of $10^{\circ}$ two-theta per minute (Webb and Longstaffe, 2000, 2002).

For determination of the silicon coordination of the amorphous silica $\left(\mathrm{Si}(\mathrm{OSi} \equiv)_{n}(\mathrm{OH})_{4-n} ; n<4\right)$ and to quantify the amount of silanol groups (Bertermann et al., 2003; Leng et al., 2009) nuclear magnetic resonance (NMR) analyses were conducted at the University of Oxford following the method of Bertermann et al. (2003). The amount of silanol groups was estimated from this analysis. For this, mass percentages for removable $-\mathrm{OH}$ groups were calculated by using the following equation:

$\mathrm{OH}_{\text {exch }}($ wt. $\%)=\mathrm{Q}_{2}(\%) \frac{\mathrm{M}(\mathrm{OH})_{2}}{\mathrm{M}\left(\mathrm{SiO}(\mathrm{OH})_{2}\right)}+\mathrm{Q}_{3}(\%) \frac{\mathrm{M}(\mathrm{OH})}{\mathrm{M}\left(\mathrm{SiO}_{1.5}(\mathrm{OH})\right)}$

where $Q n\left(\mathrm{Q}_{2}, \mathrm{Q}_{3}\right)$ represents a silicon atom and " $4-n$ " denotes the number of $-\mathrm{OH}$ groups ( $n=1$ to 4 ) surrounding the silicon atom. All other bonds are $\mathrm{Si}-\mathrm{O}-\mathrm{Si}$ and do not contribute to the percentage of exchangeable oxygen (wt.\%). $\mathrm{Q}_{1}$ was neglected as no groups of this coordination type were detected in any standard. However, this 
calculation does not take any crystallization water into account, so the results provide only an estimate of removable -OH groups.

\subsection{Methods for $\delta^{18} \mathrm{O}$ analysis}

Eight laboratories participated in the inter-laboratory comparison (Table 1). As this inter-laboratory comparison was intended to function as a method performance and a proficiency study, the four different methods used for the removal or fixing of exchangeable oxygen (iGFD, SWF, CIE, iHTR) and the different oxygen extraction techniques (laser and conventional fluorination, iHTR) were investigated. The Alfred Wegener Institute (AWI, Germany) uses inert gas flow dehydration (iGFD) with Helium (HFD). The NERC Isotope Geosciences Laboratory (NERC, UK) and the University of New Mexico (UNM, USA) employ Stepwise Fluorination (SWF). Three laboratories Weizmann Institute of Science (WIS, Israel), the University of Western Ontario (UWO, Canada) and the Centre Européen de Recherche et d'Enseignement des Géosciences de l'Environnement (CEREGE, France) - use controlled isotope exchange (CIE) while The Japan Agency for MarineEarth Science and Technology (JAMSTEC, Japan) and the Forschungszentrum Jülich (FZJ, Germany) use the inductive high-temperature carbon reduction method (iHTR).

For the oxygen extraction either conventional fluorination in nickel cylinders with a minimum of $6-8 \mathrm{mg}$ of silica (NERC, UWO, WIS), laser-fluorination with approx. $1.5 \mathrm{mg}$ of silica (AWI, WIS, CEREGE, UNM) or the iHTR method with a sample amount of approx. $0.8 \mathrm{mg}$ was used (JAMSTEC, FZJ). The isotopic analyses were performed on one of $\mathrm{O}_{2}$ (AWI, UNM, CEREGE), $\mathrm{CO}_{2}$ (NERC, UNM, UWO, WIS) or CO (JAMSTEC, FZJ) using single inlet (AWI), dual inlet (WIS, CEREGE, UWO, NERC, UNM) or continuous flow systems (JAMSTEC, FZJ). The various mass spectrometers, inlet systems and types of gases analysed are widely accepted to provide reliable results and thus, are not a topic of this paper. Details of each methods and the specific instrumentation used in each laboratory have been introduced above and are published elsewhere (see Table 1, Labeyrie, 1974; Sharp, 1990; Shemesh et al., 1992; Webb and Longstaffe, 2000; Leng et al., 2001; Lücke et al., 2005; Dodd and Sharp, 2010; Chapligin et al., 2010). All $\delta^{18} \mathrm{O}$ values from all laboratories are relative to VSMOW.

\subsection{Test design and calibration}

Between the eight laboratories it was agreed to ideally analyse each working standard at least ten times. However, the duration of sample processing varies among the laboratories and throughput ranges from 2 (e.g. 10 samples over 5 days for CIE and conventional fluorination at UWO) to 20 samples per day (iGFD and laser fluorination at AWI). For the laboratories using the CIE method, three to nine analyses for each exchange with water vapour $\left({ }^{18} \mathrm{O}\right.$-rich' and ${ }^{118} \mathrm{O}$-poor') were performed. For each standard the percentage of exchange and one $\delta^{18} \mathrm{O}$ value for the structural oxy- gen was calculated from the two mean $\delta^{18} \mathrm{O}$ values obtained when the exchangeable oxygen was exchanged with ${ }^{18} \mathrm{O}$-enriched and ${ }^{18} \mathrm{O}$-depleted vapour, respectively.

All laboratories used NBS28 $\left(\delta^{18} \mathrm{O}=+9.57 \%\right)$ as a certified standard for calibration when calculating the oxygenisotope composition of the working standards used in the inter-laboratory comparison. UWO additionally used the certified biotite standard NBS30 $(+5.12 \%)$ to perform a 2 point calibration. Further internal standards were used in each laboratory that had been previously calibrated to NBS28 on the same instrument (Campolungo, (Chapligin et al., 2010) at AWI, $+26.7 \%$; KGa-1 at UWO, $+21.5 \%$; ORX at UWO, $+11.5 \%$, SR2-1B (Dodd and Sharp, 2010) at UNM $+32.2 \%$ ). FZJ performed a 2-point calibration with NBS28 and an internal standard (Campolungo) that has a $\delta^{18} \mathrm{O}$ value of $+26.7 \%$ (Chapligin et al., 2010). Earlier results for biogenic silica $\delta^{18} \mathrm{O}$ values using a previous 2point calibration employing NBS28 and a sample of Ethmodiscus Rex (E. Rex) first analysed by Schmidt et al. (1997) (two methods: CIE $+43.5 \pm 0.2 \%$; SWF $+46.8 \pm 0.8 \%$ and assuming $+46.8 \%$ as the accurate value) deviated increasingly from the average of all laboratories when working standards with higher $\delta^{18} \mathrm{O}$ values were analysed (data set: "FZJ"). This indicates that this assumption should be revised. Re-analysis of E. Rex at the Alfred Wegener Institute $(+43.5 \pm 0.3 \%(1 \sigma), n=2)$ confirmed the $\delta^{18} \mathrm{O}$ value of Schmidt et al. (1997) using CIE. Applying the 2-point calibration with NBS28 and Campolungo the FZJ analyses for E. Rex were $+43.4 \pm 0.2 \%(n=4)$ and the $\delta^{18} \mathrm{O}$ values of the biogenic silica working standards examined in this study were then in agreement with the averages obtained from the other laboratories. Therefore, all results used in this comparison from FZJ were recalibrated with NBS28 $(+9.6 \%$ ) and E. Rex $(+43.4 \%$ ) (data set: "FZJ rec"). All other internal standards additionally used in the laboratories during this inter-laboratory comparison were found within a SD of $0.2-0.3 \%$ and thus, verify the reliability of previous results.

\subsection{Statistical treatment of data}

Normal distributions of the results within one laboratory's set and of all means of the sets were tested by applying a David Test:

$$
G=\frac{X_{\max }-X_{\min }}{\mathrm{SD}}
$$

where $G$ is the test statistics (significance level $\alpha=0.05$, depending on $n$ ) and SD the standard deviation. For the laboratories using the CIE method the David test was applied to the results of both exchanges $\left(\mathrm{CIE}_{1}, \mathrm{CIE}_{2}\right)$. For data sets with only a few repetitions the test might not be significant, given the limited number of analyses performed $(3 \leqslant n \leqslant 19)$.

After the verification of a normal distribution a Grubbs' Test was applied to detect two kinds of outliers: (1) Outlying results for individual laboratories were removed and not taken into account when calculating the mean $\delta^{18} \mathrm{O}$ value for a given working standard for that laboratory. (2) Mean values from a given laboratory that deviated unacceptably 
from other laboratories were excluded and the pooled values calculated without these outliers. The Grubbs' tests were iterated until no outlier was detected according to the following formula:

$$
G=\frac{\left|x_{i}-\bar{x}\right|}{\mathrm{SD}}
$$

where $G$ is the test statistics (significance level $\alpha=0.05$, depending on $n$ ) and $x$ and SD denote the sample mean and standard deviation, respectively.

The laboratories using the CIE method provided between three and nine results for each exchange for which the mean and the standard deviation from both exchanges were calculated and mass-balance corrections applied to determine the percentage of exchangeable oxygen $(\mathrm{X})$ and the final $\delta^{18} \mathrm{O}$ values. For better comparability with results from the other laboratories, all theoretically possible pairs from the two exchanges were selected for calculation of $\mathrm{X}$ and for the standard deviation of the final $\delta^{18} \mathrm{O}$ values. Using this approach the mean values remained the same, whereas the standard deviations were generally lower than the mean standard deviation calculated separately for $\mathrm{SD}_{\mathrm{CIE} 1}$ and $\mathrm{SD}_{\mathrm{CIE} 2}$.

A working standards-versus-laboratories spreadsheet containing normalized mean values was used as an input data matrix for multivariate analyses. Non-metric multidimensional scaling (nmMDS) is an effective tool to explore the patterns of variation in multivariate data sets. NmMDS provides an optimal low dimensional mapping that preserves the rank ordering of sites while avoiding the assumption of data normality (Kruskal, 1964; Clarke and Ainsworth, 1993). Calculation of the dissimilarity matrix was performed using Euclidean distance as dissimilarity measure; missing values were excluded from the distance (a)

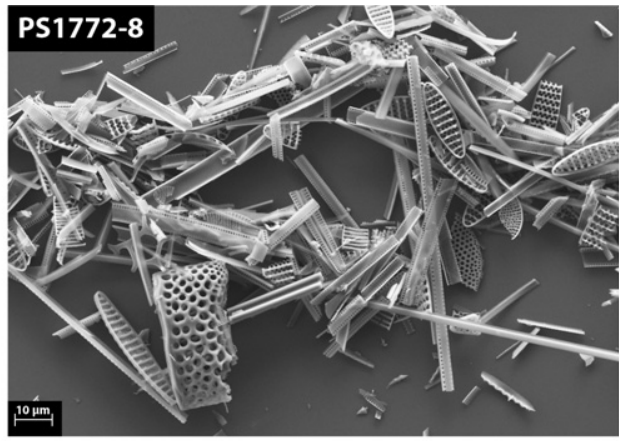

(c)

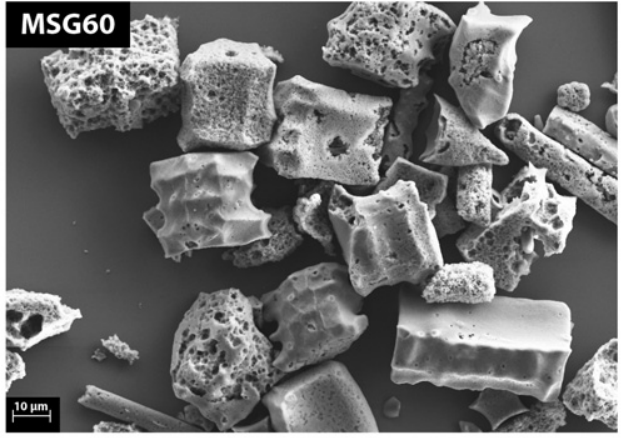

(e)

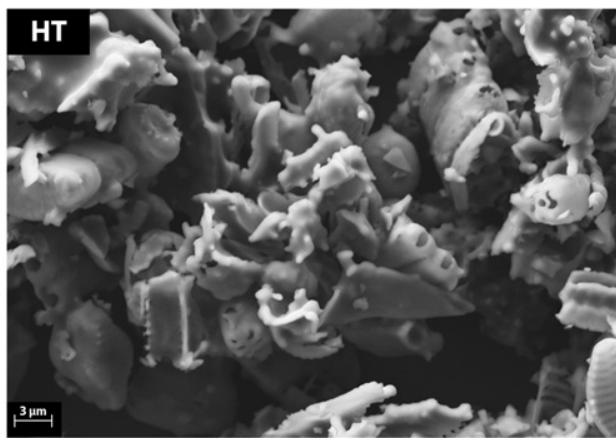

(b)

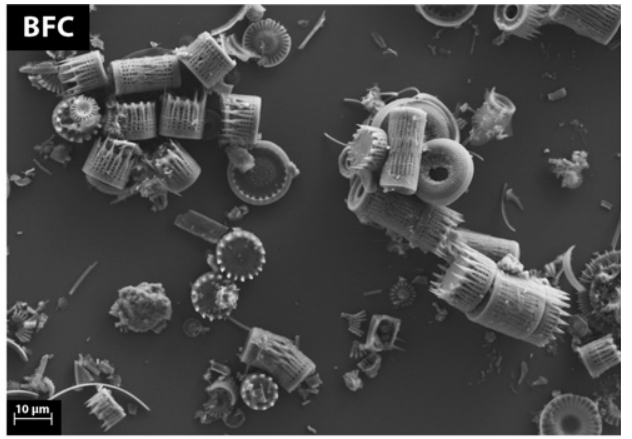

(d)

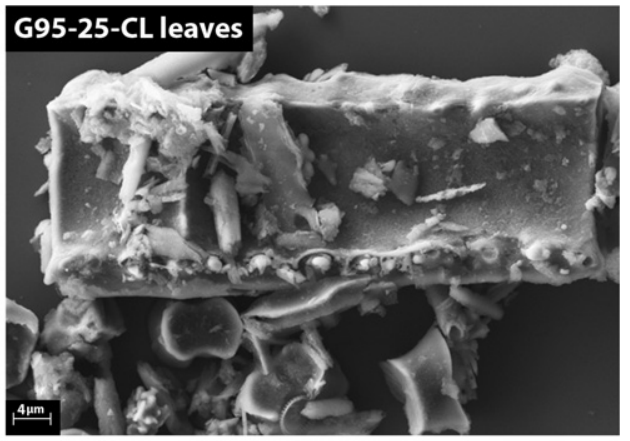

(f)

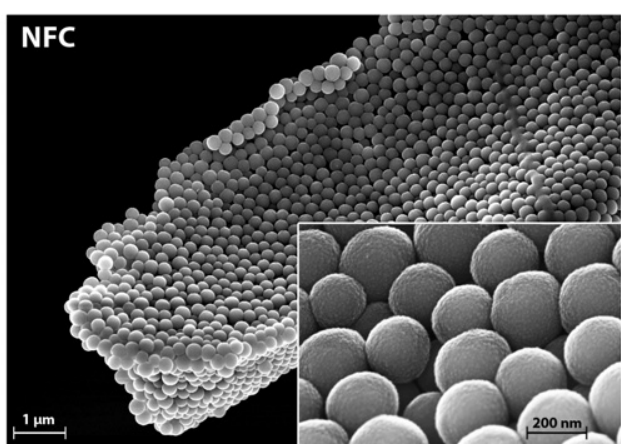

Fig. 1. SEM photomicrographs of the standards. Top (a and b): 2 diatom working standards (PS1772-8, BFC), middle (c and d): 2 phytolith working standards (MSG60, G95-25-CL-leaves), bottom left (e): calcinated Merck Kieselgur (HT), bottom right (f): synthetically-produced amorphous silica and its nano-structure (NFC). 
calculations. NmMDS was run on two, three and four dimensions, respectively, to test the stress value, which is an indicator for the goodness of fit between original distances and fitted values. The three- and four-dimensional model produced an insignificant reduction in stress, and thus a two-dimensional model, being the most parsimonious model, was chosen. Patterns of variation in laboratories as well as in working standards were investigated.

\section{RESULTS AND DISCUSSION}

\subsection{Standard purity}

SEM photomicrographs (Fig. 1) provide a detailed visual impression of all working standards (note the different scales). They reveal a greater amount of extraneous material in working standard PS1772-8 (Fig. 1a) than in working standard BFC (Fig. 1b). Grass phytoliths are shown in MSG60 (Fig. 1c) and G95-25-CL-leaves (Fig. 1d). The glossy surface of the HT Kieselgur working standard (Fig. 1e) results from calcination, a process during which the working standard is heated to $1050{ }^{\circ} \mathrm{C}$ for several hours. The nano-spheres of the working standard NFC are resolved clearly and have a size of approx. $200 \mathrm{~nm}$ (Fig. 1f). The XRF results in Table 3 show that the normalized $\mathrm{SiO}_{2}$ percentages are $>99 \%$ for all of the proposed working standards except HT (94.2\%) and BFC (97.2\%). The low percentage total for NFC $(95.02 \%)$ can be attributed to the difficulty in getting precipitated amorphous silica to form a fused bead. For $\mathrm{HT}, \mathrm{Al}_{2} \mathrm{O}_{3}, \mathrm{Na}_{2} \mathrm{O}$ and $\mathrm{Fe}_{2} \mathrm{O}_{3}$ contents are greater than $1.4 \%$ each, indicating a contamination by either clay or artificial additives such as soda used in the calcination process. BFC has a high aluminum content $(2.1 \%)$ possibly resulting from low abundances of impurities e.g. traces of clay that might be poorly crystalline and not detectable by XRD. Total carbon (TC) concentrations were low $(<0.5 \%$, detection limit: $0.05 \%)$ for all working standards as were total nitrogen $(\mathrm{TN})$ concentrations (below detection limit $<0.1 \%$ ) except for working standard
NFC $(\mathrm{TN}=0.8 \%)$, which likely reflects the ammonia solution in which the spheres were precipitated. Total sulfur concentrations were $<0.2 \%$ in all working standards (detection limit: $0.05 \%$ ). Generally, all working standards, except for HT and BFC, are of extremely high purity. Thus, the suitability of any proposed material as a working standard for oxygen-isotope analyses depends principally on the reproducibility of its $\delta^{18} \mathrm{O}$ values across the various methods tested here.

\subsection{Standard structure}

Since the TC analyses show that carbon did not contribute significantly to the LOI, the LOI must indicate varying amounts of hydroxyl groups and crystallization water among the working standards. HT contains almost no exchangeable oxygen $(\mathrm{LOI}=0.35 \%)$ whereas NFC has the highest content $(5.47 \%)$ of hydroxyl groups and crystallization water to be removed prior to analysis. Powder XRD and NMR results can be used to obtain further insight into this variation. Jones et al. (1964) first demonstrated with XRD spectra that opals can have a wide structural range from amorphous to crystalline. Here, the XRD analyses revealed that five (BFC, PS1772-8, MSG60, G95, NFC) out of six working standards have a broad, pure amorphous silica (opal-A) peak (Fig. 2). Sample G95-25-CL leaves also contains a small quartz peak with a d-spacing of $0.334 \mathrm{~nm}$. However, the height of this diffraction peak, the most intense for quartz, is very small; hence, the contamination is negligible. Additionally, no issues with heterogeneity were observed in the previous oxygen-isotope analyses of this working standard (Webb and Longstaffe, 2002). The diffraction pattern for HT matches that of cristobalite, which likely developed during the calcination process. That said, the full width at half maximum (FWHM) of typical cristobalite peaks is narrower, e.g. at the largest peak (d-spacing $=0.406 \mathrm{~nm} ; \mathrm{FWHM}_{\text {cristobalite }}=0.015 \mathrm{~nm}$; $\mathrm{FWHM}_{\mathrm{HT}}=0.034 \mathrm{~nm}$ ). In addition, the shoulder

Table 3

XRF results (in wt.\%) for the working standards. After subtracting the loss on ignition (LOI) and normalizing the contents to $100 \%$, the working standards show $\mathrm{SiO}_{2}$ percentages between $94.23 \%$ and $99.99 \%$.

\begin{tabular}{|c|c|c|c|c|c|c|c|c|c|c|c|c|c|}
\hline Standard & $\mathrm{SiO}_{2}$ & $\mathrm{TiO}_{2}$ & $\mathrm{Al}_{2} \mathrm{O}_{3}$ & $\mathrm{Fe}_{2} \mathrm{O}_{3} \mathrm{t}$ & $\mathrm{Mn}_{3} \mathrm{O}_{4}$ & $\mathrm{MgO}$ & $\mathrm{CaO}$ & $\mathrm{Na}_{2} \mathrm{O}$ & $\mathrm{K}_{2} \mathrm{O}$ & $\mathrm{P}_{2} \mathrm{O}_{5}$ & $\mathrm{SO}_{3}$ & LOI & Total \\
\hline PS & 94.92 & $<0.01$ & 0.09 & 0.02 & $<0.01$ & $<0.05$ & 0.03 & 0.27 & 0.08 & $<0.01$ & $<0.1$ & 3.30 & 98.71 \\
\hline $\mathrm{BFC}$ & 92.53 & 0.09 & 2.01 & 0.43 & 0.001 & 0.06 & 0.07 & $<0.05$ & 0.05 & $<0.01$ & $<0.1$ & 4.27 & 99.51 \\
\hline MSG60 & 94.78 & 0.19 & 0.16 & 0.20 & 0.01 & $<0.05$ & 0.08 & 0.06 & 0.07 & $<0.01$ & $<0.1$ & 3.71 & 99.26 \\
\hline G95 & 92.52 & 0.02 & 0.32 & 0.02 & $<0.01$ & $<0.05$ & 0.09 & 0.22 & 0.14 & $<0.01$ & 0.1 & 5.23 & 98.66 \\
\hline HT & 93.28 & 0.22 & 1.41 & 1.45 & 0.01 & 0.15 & 0.52 & 1.74 & 0.08 & 0.13 & $<0.1$ & 0.35 & 99.34 \\
\hline NFC & 89.54 & $<0.01$ & $<0.01$ & 0.01 & $<0.01$ & $<0.05$ & $<0.01$ & $<0.05$ & $<0.01$ & $<0.01$ & $<0.1$ & 5.47 & 95.02 \\
\hline Standard & $\mathrm{SiO}_{2}$ & $\mathrm{TiO}_{2}$ & $\mathrm{Al}_{2} \mathrm{O}_{3}$ & $\mathrm{Fe}_{2} \mathrm{O}_{3} \mathrm{t}$ & $\mathrm{Mn}_{3} \mathrm{O}_{4}$ & $\mathrm{MgO}$ & $\mathrm{CaO}$ & $\mathrm{Na}_{2} \mathrm{O}$ & $\mathrm{K}_{2} \mathrm{O}$ & $\mathrm{P}_{2} \mathrm{O}_{5}$ & $\mathrm{SO}_{3}$ & Total & \\
\hline PS & 99.49 & bdl & 0.09 & 0.02 & bdl & bdl & 0.03 & 0.28 & 0.08 & bdl & bdl & 100.00 & \\
\hline $\mathrm{BFC}$ & 97.15 & 0.09 & 2.11 & 0.45 & 0.00 & 0.06 & 0.07 & bdl & 0.05 & bdl & bdl & 100.00 & \\
\hline MSG60 & 99.19 & 0.20 & 0.17 & 0.21 & 0.01 & bdl & 0.08 & 0.06 & 0.07 & bdl & bdl & 100.00 & \\
\hline G95 & 99.03 & 0.02 & 0.34 & 0.02 & bdl & bdl & 0.10 & 0.24 & 0.15 & bdl & 0.11 & 100.00 & \\
\hline HT & 94.23 & 0.22 & 1.42 & 1.46 & 0.01 & 0.15 & 0.53 & 1.76 & 0.08 & 0.13 & bdl & 100.00 & \\
\hline
\end{tabular}

$\mathrm{bdl}=$ below detection limit. 


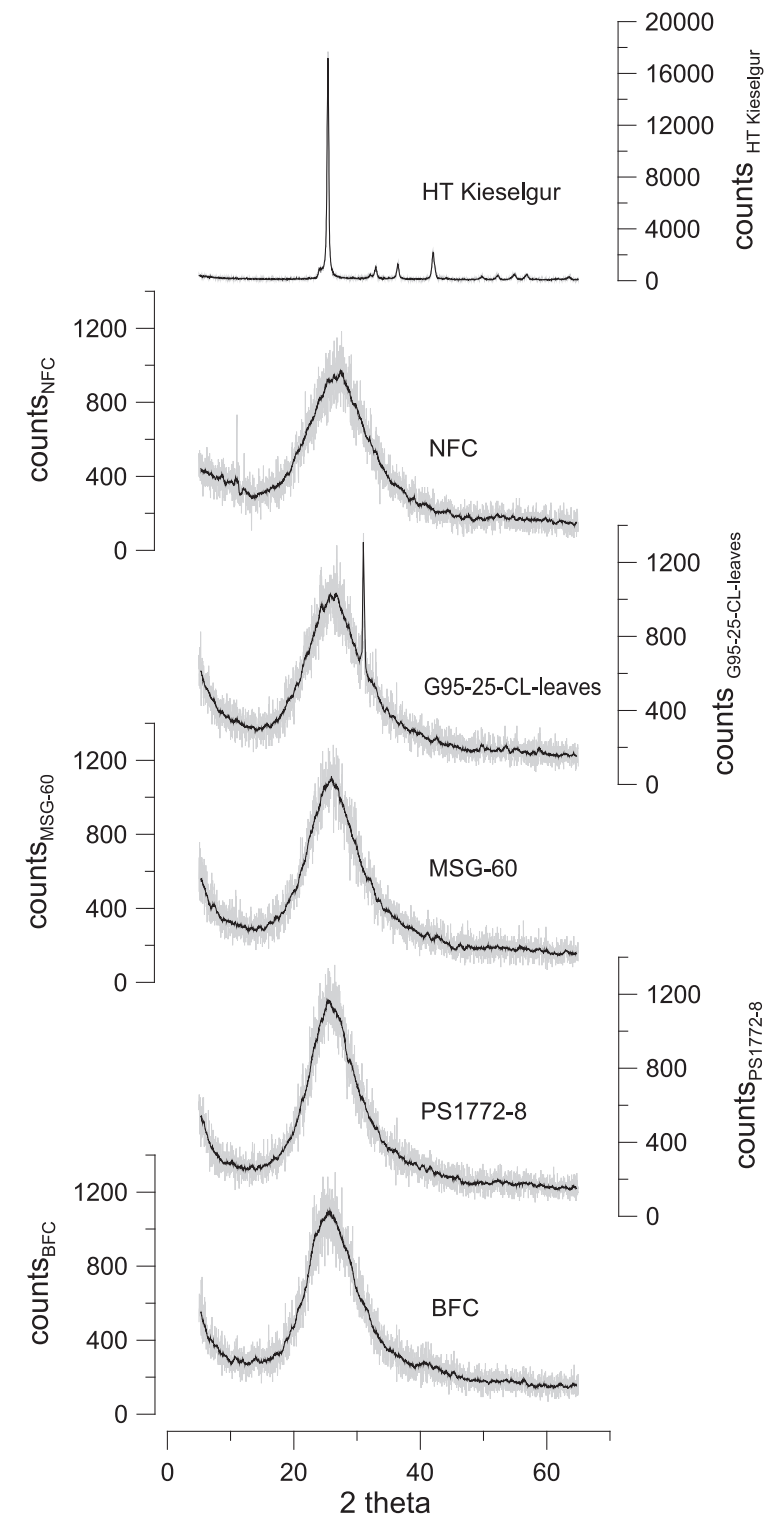

Fig. 2. XRD scans of the working standards (grey) and running average with a window width of 31 data points (black): HT Kieselgur has a crystalline structure (opal-CT); all other working standards show broad peaks of typical opal-A (amorphous silica).

$(0.421 \mathrm{~nm})$ on the largest peak $(0.406 \mathrm{~nm})$ indicates that there is some tridymite ordering within the opal, as it has been observed in other studies where opal was heated in the laboratory (Rice et al., 1995). Hence, HT has been characterized as opal-CT and LOI data verify that no exchangeable oxygen is present.

Silicon coordination was assessed by NMR analysis (Table 4a) and the mass percentages for removable $-\mathrm{OH}$ groups were calculated. In a comparison of LOI and NMR results the same three clusters emerged: HT $(0 \%$ LOI and $0 \%$ exchangeable oxygen calculated by NMR); MSG, BFC and PS (3-5\% LOI; 5-10\% NMR); G95 and NFC ( $>5 \% \mathrm{LOI} ;>10 \% \mathrm{NMR})$. This distinction is of importance when comparing the percentages of $-\mathrm{OH}$ removal among the different methods (Table 4b).
Table 4a

NMR analysis and calculated -OH group content (wt.\%) of the working standards.

\begin{tabular}{llcclr}
\hline Standard & $\mathrm{Q}_{2}(\%)$ & $\mathrm{Q}_{3}(\%)$ & $\mathrm{Q}_{4}(\%)$ & $\mathrm{Q}_{4} / \mathrm{Q}_{3}$ & Calc. exch. $-\mathrm{OH}$ \\
\hline PS & 2.7 & 30.3 & 67.0 & 2.2 & 9.6 \\
BFC & 0.5 & 21.9 & 77.7 & 3.6 & 6.3 \\
MSG60 & 0.5 & 35.3 & 64.2 & 1.8 & 9.7 \\
G95 & 0.9 & 40.1 & 59.0 & 1.5 & 11.1 \\
HT & 0.0 & 0.0 & 100.0 & X & 0.0 \\
NFC & 0.2 & 70.0 & 29.8 & 0.4 & 18.0 \\
\hline
\end{tabular}

Table $4 \mathrm{~b}$

Percent material removed (SWF), water loss from dehydration (iGFD) or amount of exchangeable oxygen that was fixed prior to oxygen-isotope analyses of the working standards (CIE) in each laboratory $(\%)$ calculated from volume change (SWF), mass loss (iGFD) or mass balancing (CIE). The laboratories using iHTR devices (JAMSTEC, FZJ) cannot determine this parameter prior to analysis.

\begin{tabular}{|c|c|c|c|c|c|c|}
\hline \multirow{2}{*}{$\begin{array}{l}\text { Method } \\
\text { Standard }\end{array}$} & \multirow{2}{*}{$\begin{array}{l}\text { iGFD } \\
\text { AWI }\end{array}$} & \multicolumn{2}{|c|}{ SWF } & \multicolumn{3}{|c|}{ CIE } \\
\hline & & NERC & UNM & WIS & UWO & CER \\
\hline PS & 8.3 & 25.5 & 20 & 2.4 & 6.4 & 14.4 \\
\hline $\mathrm{BFC}$ & 8.2 & 28.9 & 15 & 2.1 & 0.9 & 5 . \\
\hline MSG60 & 8.8 & 28.9 & 28 & 0.2 & 3.3 & 4.2 \\
\hline G95 & 10.8 & 27.5 & 14 & 0.5 & 5.5 & 13.7 \\
\hline HT & 0.2 & 13.8 & 12 & 2.6 & 0.6 & 13. \\
\hline NFC & 11.6 & 25.6 & 40 & 6.8 & 2.7 & 10.0 \\
\hline
\end{tabular}

In summary, the structural analyses identified the HT Kieselgur working standard as crystalline (opal-CT) and thus, free of exchangeable oxygen. This working standard therefore provides a test of whether additional oxygen from the $\mathrm{Si}-\mathrm{O}-\mathrm{Si}$ structure was removed or exchanged during individual laboratory procedures, apart from exchangeable oxygen associated with $\mathrm{Si}-\mathrm{OH}$ groups. All other working standards have a similar range of LOI (3-6\%), display amorphous XRD spectra and contain different amounts of exchangeable oxygen.

\subsection{Method performance}

Results from laboratories using the same method were compared both for the amount of oxygen fixed or removed during dehydration (Table $4 \mathrm{~b}$ ) and the $\delta^{18} \mathrm{O}$ values obtained for each working standard (Fig. 3 and Table 5), as described below.

\subsubsection{Stepwise fluorination ( $S W F$ )}

Although the same approach for the removal of exchangeable oxygen is applied by NERC and UNM, different reagents are used (NERC: $\mathrm{BrF}_{5} ; \mathrm{UNM}: \mathrm{F}_{2}$ ). Similar $\delta^{18} \mathrm{O}$ values were obtained for both laboratories for all working standards except for the synthetically produced NFC. NFC reacted vigorously with the $\mathrm{F}_{2}$ during the prefluorination stage. Thus, only minimal prefluorination could be applied resulting in an incomplete removal of exchangeable oxygen and lower $\delta^{18} \mathrm{O}$ values (UNM NFC $\delta^{18} \mathrm{O}=20.5 \%$; pooled NFC $\delta^{18} \mathrm{O}=27.0 \%$ ). Therefore the NFC determined at UNM was considered an outlier. Fig. 3 shows that the 


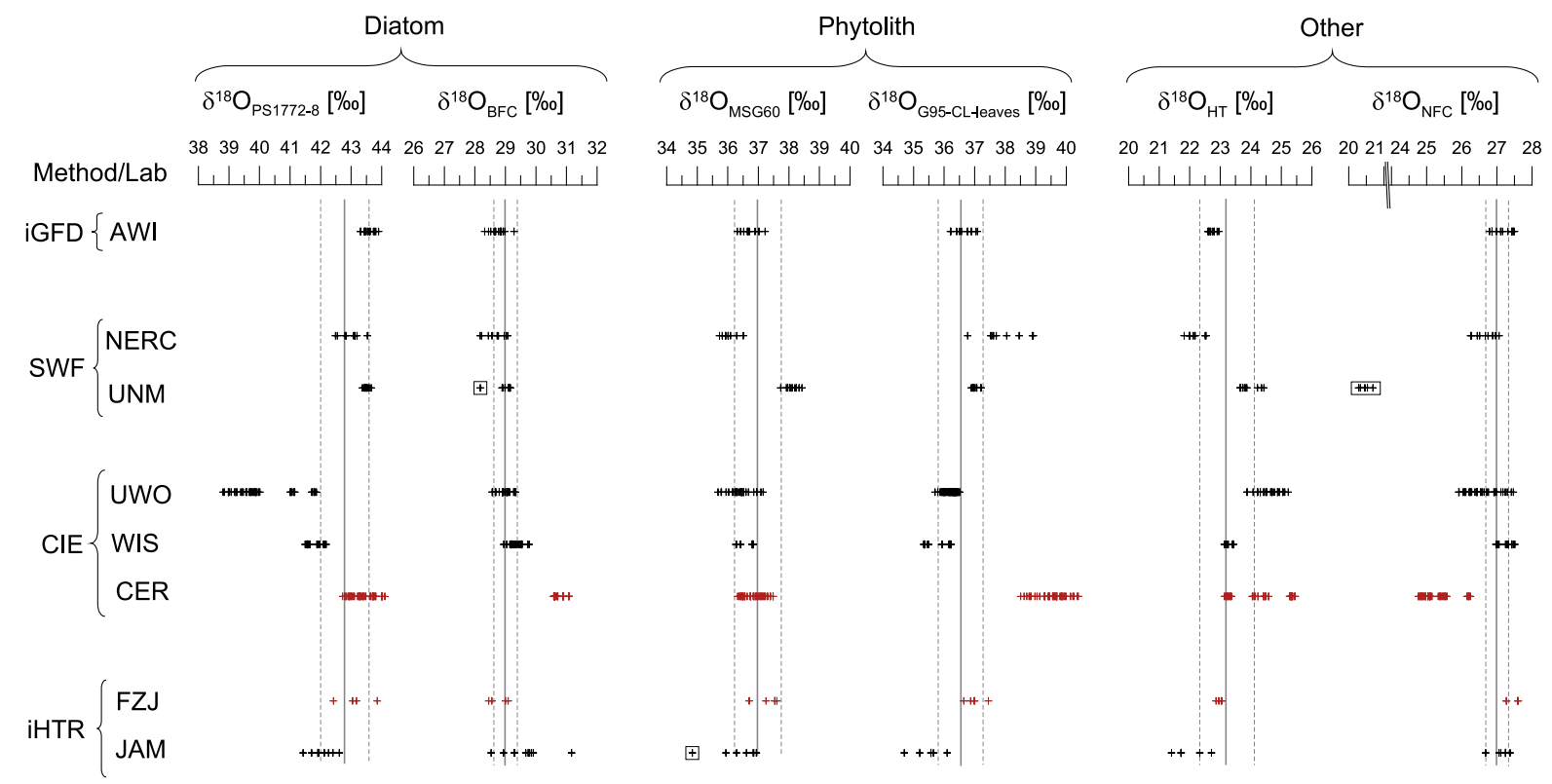

Fig. 3. Summary of $\delta^{18} \mathrm{O}$ values from each laboratory. Methods and type of working standards are grouped to simplify comparison. Outliers $(\square)$, the pooled mean $\delta^{18} \mathrm{O}$ value (solid line) and the standard deviation from the mean (broken line, $1 \sigma$ on both sides) are marked. CEREGE applied corrections to the original data and FZJ recalibrated measurements (both corrected data sets: red crosses/in the print version in grey). Note the break and different scale on the $\delta^{18} \mathrm{O}_{\mathrm{NFC}}$ axis.

Table 5

Summary of the oxygen-isotope results from all groups relative to VSMOW. For the laboratories applying CIE, all possible pairs from exchange 1 and exchange 2 were combined resulting in a higher $\mathrm{n}$ than analysed. Standard deviations and $\mathrm{n}$ are given for both exchanges (in brackets) and for all pairs. Pooled values are calculated from mean values of all laboratories excluding outlying groups (marked ${ }^{*}$ ) and values before correction/recalibration (CEREGE/FZJ, marked in grey).

\begin{tabular}{|c|c|c|c|c|}
\hline$\underline{\text { Standard }}$ & Group & $\delta^{18} \mathrm{O}(\% \mathrm{oo})$ & $\operatorname{SD}(1 \sigma)(\%)$ & $n$ \\
\hline PS1772-8 & AWI & 43.6 & 0.2 & 15 \\
\hline PS1772-8 & NERC & 43.0 & 0.3 & 9 \\
\hline PS1772-8 & UNM & 43.5 & 0.1 & 10 \\
\hline PS1772-8 & UWO $^{*}$ & 40.2 & $0.9(1.0 / 1.2)$ & $42(7 / 6)$ \\
\hline PS1772-8 & WIS & 41.8 & $0.3(0.3 / 0.2)$ & $16(4 / 4)$ \\
\hline PS1772-8 & CEREGE $^{*}$ & 46.4 & $0.4(0.6 / 0.3)$ & $36(6 / 6)$ \\
\hline PS1772-8 & CEREGE corr ${ }^{*}$ & 43.4 & $0.4(0.6 / 0.3)$ & $36(6 / 6)$ \\
\hline PS1772-8 & JAMSTEC & 42.0 & 0.3 & 10 \\
\hline PS1772-8 & FZJ & 46.5 & 0.7 & 4 \\
\hline PS1772-8 & FZJ rec & 43.1 & 0.6 & 4 \\
\hline PS1772-8 & Pooled $^{* *}$ & 42.8 & 0.8 & 6 \\
\hline $\mathrm{BFC}$ & AWI & 28.8 & 0.3 & 19 \\
\hline $\mathrm{BFC}$ & NERC & 28.7 & 0.3 & 9 \\
\hline $\mathrm{BFC}$ & UNM & 29.1 & 0.1 & 9 \\
\hline $\mathrm{BFC}$ & UWO & 29.0 & $0.2(0.2 / 0.6)$ & $25(5 / 5)$ \\
\hline $\mathrm{BFC}$ & WIS & 29.4 & $0.2(1.0 / 0.2)$ & $16(4 / 4)$ \\
\hline $\mathrm{BFC}$ & CEREGE $^{*}$ & 32.8 & $0.1(0.2 / 0.1)$ & $24(6 / 4)$ \\
\hline $\mathrm{BFC}$ & CEREGE corr ${ }^{*}$ & 30.8 & $0.1(0.2 / 0.1)$ & $24(6 / 4)$ \\
\hline $\mathrm{BFC}$ & JAMSTEC & 29.4 & 0.9 & 12 \\
\hline $\mathrm{BFC}$ & FZJ & 30.7 & 0.4 & 4 \\
\hline $\mathrm{BFC}$ & FZJ rec & 28.8 & 0.3 & 4 \\
\hline BFC & Pooled $^{* *}$ & 29.0 & 0.3 & 7 \\
\hline MSG60 & AWI & 36.7 & 0.3 & 9 \\
\hline MSG60 & NERC & 36.1 & 0.2 & 10 \\
\hline MSG60 & UNM & 38.1 & 0.2 & 10 \\
\hline MSG60 & UWO & 36.4 & $0.4(0.5 / 0.8)$ & $25 / 5 / 5)$ \\
\hline MSG60 & WIS & 36.6 & $0.3(0.4 / 0.3)$ & $16(4 / 4)$ \\
\hline MSG60 & CEREGE & 38.1 & $0.4(0.4 / 0.4)$ & $36(6 / 6)$ \\
\hline MSG60 & CEREGE corr & 36.9 & $0.4(0.4 / 0.4)$ & $36(6 / 6)$ \\
\hline
\end{tabular}


Table 5 (continued)

\begin{tabular}{|c|c|c|c|c|}
\hline Standard & Group & $\delta^{18} \mathrm{O}(\%)$ & $\operatorname{SD}(1 \sigma)(\%)$ & $n$ \\
\hline MSG60 & JAMSTEC & 36.3 & 0.8 & 7 \\
\hline MSG60 & FZ JÜLICH & 40.1 & 0.5 & 4 \\
\hline MSG60 & FZ JÜLICH rec & 37.3 & 0.4 & 4 \\
\hline MSG60 & Pooled $^{* *}$ & 37.0 & 0.8 & 8 \\
\hline G95 & AWI & 36.7 & 0.3 & 9 \\
\hline G95 & NERC & 37.9 & 0.7 & 10 \\
\hline G95 & UNM & 37.0 & 0.1 & 10 \\
\hline G95 & UWO & 36.2 & $0.2(0.2 / 0.5)$ & $54(6 / 9)$ \\
\hline G95 & WIS & 35.8 & $0.4(0.5 / 0.4)$ & $16(4 / 4)$ \\
\hline G95 & CEREGE* & 43.0 & $0.7(0.5 / 0.5)$ & $35(7 / 5)$ \\
\hline G95 & CEREGE corr ${ }^{*}$ & 39.5 & $0.7(0.5 / 0.5)$ & $35(7 / 5)$ \\
\hline G95 & JAMSTEC & 35.4 & 0.5 & 5 \\
\hline G95 & FZJ & 39.7 & 0.3 & 4 \\
\hline G95 & FZJ rec & 37.0 & 0.3 & 4 \\
\hline G95 & Pooled $^{* *}$ & 36.6 & 0.8 & 7 \\
\hline HT & AWI & 22.7 & 0.1 & 9 \\
\hline HT & NERC & 22.1 & 0.2 & 10 \\
\hline HT & UNM & 23.9 & 0.3 & 10 \\
\hline HT & UWO & 24.6 & $0.4(0.6 / 0.6)$ & $25(5 / 5)$ \\
\hline HT & WIS & 23.3 & $0.1(0.4 / 0.0)$ & $9(3 / 3)$ \\
\hline HT & CEREGE $^{*}$ & 30.3 & $0.6(0.6 / 0.6)$ & $36(6 / 6)$ \\
\hline HT & CEREGE corr ${ }^{*}$ & 24.3 & $0.6(0.6 / 0.6)$ & $36(6 / 6)$ \\
\hline HT & JAMSTEC & 22.4 & 0.7 & 10 \\
\hline HT & FZJ & 24.4 & 0.3 & 6 \\
\hline HT & FZJ rec & 23.0 & 0.1 & 6 \\
\hline HT & Pooled $^{* *}$ & 23.2 & 0.9 & 7 \\
\hline NFC & AWI & 27.2 & 0.3 & 9 \\
\hline NFC & NERC & 26.6 & 0.3 & 9 \\
\hline NFC & $\mathrm{UNM}^{*}$ & 20.5 & 0.2 & 5 \\
\hline NFC & UWO & 26.6 & $0.4(0.7 / 0.5)$ & $35(7 / 5)$ \\
\hline NFC & WIS & 27.3 & $0.2(0.2 / 0.3)$ & $12(4 / 3)$ \\
\hline $\mathrm{NFC}$ & CEREGE ${ }^{*}$ & 29.7 & $0.2(0.3 / 0.3)$ & $36(6 / 6)$ \\
\hline NFC & CEREGE corr ${ }^{*}$ & 25.3 & $0.2(0.3 / 0.3)$ & $36(6 / 6)$ \\
\hline $\mathrm{NFC}$ & JAMSTEC & 27.1 & 0.3 & 5 \\
\hline NFC & FZJ & 29.2 & 0.2 & 4 \\
\hline $\mathrm{NFC}$ & FZJ rec & 27.4 & 0.2 & 4 \\
\hline NFC & Pooled ${ }^{* *}$ & 27.0 & 0.3 & 6 \\
\hline
\end{tabular}

* Outliers (marked CEREGE corr values are based on outlier data; defined as outliers).

** Calculated from laboratories' mean values excl. outliers.

$\delta^{18} \mathrm{O}$ values produced by NERC are lower than those of UNM for 4 of the 5 working standards (excluding NFC). This may suggest that the use of $\mathrm{BrF}_{5}$ to remove hydrous groups could lead to lower $\delta^{18} \mathrm{O}$ values caused by insufficient reaction temperatures or reaction times as stated in Garlick and Epstein (1967). Apart from NFC, UNM removes more material during prefluorination than NERC (Table 4b). However, the lower $\delta^{18} \mathrm{O}$ values obtained by NERC are unlikely a consequence of incomplete removal as the $\delta^{18} \mathrm{O}$ values in both laboratories reached a plateau (Leng et al., 2001; Dodd and Sharp, 2010). Additionally, lower $\delta^{18} \mathrm{O}$ values can be caused when smaller rather than larger sample amounts are used (Mattey and Macpherson, 1993; Chapligin et al., 2010) but NERC uses an approx. $7 \mathrm{mg}$ sample versus approx. $1.5 \mathrm{mg}$ at UNM. Notwithstanding these variations and excluding the NFC data, both data sets produce average $\delta^{18} \mathrm{O}$ values that are within one standard deviation of the average results from all laboratories and both approaches deliver comparable data (Table 5).

\subsubsection{Controlled isotopic exchange (CIE)}

The laboratories using CIE are WIS, UWO and CEREGE. WIS applied laser-fluorination using $\mathrm{BrF}_{5}$ with lower amounts of sample $\left(0.2-0.3 \mathrm{mg}\right.$, analysing $\left.\mathrm{CO}_{2}\right)$ for CIE 1 and conventional fluorination for CIE 2 (3-4 mg, analysing $\mathrm{O}_{2}$ ). The results show that higher reproducibility can be achieved with higher initial sample weights (conventional fluorination, mean $\mathrm{SD}=0.24 \%, 1 \sigma$ ) compared to lower initial weights (laser-fluorination, mean $\mathrm{SD}=0.48 \%, 1 \sigma$ ).

UWO applies conventional fluorination using $\mathrm{ClF}_{3}$ for analysis while CEREGE uses laser fluorination with $\mathrm{BrF}_{5}$. Borthwick and Harmon (1982) found that no differences in $\delta^{18} \mathrm{O}$ values accompany the use of one reagent versus the other. A test conducted at UWO during this inter-laboratory comparison using $\mathrm{G} 95$ confirmed this result $\left(\mathrm{BrF}_{5}\right.$ : $+36.3 \%, n=8, \mathrm{SD}=0.1 \%, 1 \sigma ; \mathrm{ClF}_{3}:+36.1 \%, n=20$, $\mathrm{SD}=0.2 \%, 1 \sigma)$.

The percentage of exchanged hydrous groups varies significantly among the different laboratories using CIE 
(Table $4 b$ ). UWO and WIS report $0.5 \%$ to $6.5 \%$ exchangeable oxygen whereas CEREGE estimates between $4 \%$ and $14 \%$. Differences also exist between the UWO and WIS results: The highest percentage calculated by WIS matches the structural observations that working standard NFC is the most hydrous, whereas UWO reported the highest percentage of exchangeable oxygen for working standard PS1772-8. UWO's lowest percentage of exchanged oxygen was determined for the crystalline working standard HT $(0.57 \%)$ whereas WIS detected less than $0.52 \%$ of exchanged oxygen only for working standards MSG60 and G95. These differences underline the hypothesis of Schmidt et al. (1997) that the exchangeability of silica is variable using the CIE method.

Despite the different percentages of removed exchangeable oxygen the data sets from UWO and WIS show a mean absolute offset of $0.6 \%$ in their mean $\delta^{18} \mathrm{O}$ values (excluding the standard PS1772-8 from UWO) and are within the pooled standard deviation of all laboratories. The mean $\delta^{18} \mathrm{O}$ value of PS1772-8 analysed by UWO was considered as an outlier compared to all other laboratories.

The mean $\delta^{18} \mathrm{O}$ values of the silica standards analysed by CEREGE were significantly different from the results obtained by UWO and WIS. The mean $\delta^{18} \mathrm{O}$ values of working standards at CEREGE (except working standard MSG60) were treated as outliers (Table 5). It also appeared that analyses of working standards by CEREGE with higher calculated percentages of exchangeable oxygen had $\delta^{18} \mathrm{O}$ values that deviated even further from the pooled values $\left(R^{2}=0.50\right)$. Hence, an effort to correct for a systematic error was undertaken (c.f. section: correction for CEREGE values).

\subsubsection{Inductive high-temperature carbon reduction (iHTR)}

JAMSTEC and FZJ both apply the iHTR method. Percentages of removed oxygen are not quantified using this method in its current setup. The amount of analyte generated (pressure gauge) in relation to sample dry weight can be used as relative estimate for removed oxygen. Since the iHTR analyses are carried out in a continuous-flow setup, it is preferable to use a two-point calibration method and replicate analyses to account for the performance of the instrument and sample inhomogeneities. Differences in the reproducibility of $\delta^{18} \mathrm{O}$ values obtained with the iHTR method (Table 5) between JAMSTEC and FZJ potentially arise from the comparably low quantity of sample analysed (JAMSTEC: $0.2-0.5 \mathrm{mg}$; FZJ: $0.8 \mathrm{mg}$ ) and a resulting increased influence of sample heterogeneity. To account for this, FZJ performs replicate analyses of samples and standards to verify the results and to allow calculation of a standard deviation for every sample. Due to this routine, every result reported from FZJ is based on 2-5 replicates each with ca. 20-25 analyses performed per day. Replicate analyses also account for small memory effects that partly arise when materials with a large isotope offset $(>10 \%)$ are measured consecutively. Two-point calibrations are recommended for all laboratories especially when using the iHTR method.

Beside the difference in reproducibility, both iHTR data sets are comparable with a mean absolute offset of $0.8 \%$ in their mean $\delta^{18} \mathrm{O}$ values. Since the offset between the data sets rises with the absolute $\delta^{18} \mathrm{O}$ values the difference could be partly due to the calibration methods used. No outliers of mean $\delta^{18} \mathrm{O}$ values were detected when compared to the pooled $\delta^{18} \mathrm{O}$ values from all laboratories and both data set are within the standard deviation of all laboratories values.

\subsection{Proficiency study}

The different methods (iGFD, SWF, CIE, iHTR) used to remove or fix hydrous groups were assessed by comparing the oxygen loss resulting from the treatment or percent exchanged (Table 4b) and the resulting $\delta^{18} \mathrm{O}$ values (Fig. 3; Table 5). The SWF method removes by far the most material (average volume loss during standard analyses in both laboratories is $22 \%$, excluding outliers). In addition to the exchangeable oxygen from hydrous groups, oxygen from inner opal-A structure is also removed by this method. However, as the final $\delta^{18} \mathrm{O}$ values are similar to those obtained with other methods, it is evident that removal of the hydrous plus some structural oxygen does not result in fractionation of the residual stable oxygen (Matheney and Knauth, 1989).

AWI is the only laboratory in this study to utilize inert Gas Flow Dehydration. The percentage of hydrous groups removed by this method $(0.2-11.6 \%)$ provides a reasonable match to the three clusters of volatile content defined by the LOI (Table 3) and NMR analyses (Table 4a). The percentages of exchanged oxygen calculated by the laboratories using CIE varies (UWO/WIS: 0.5-6.8\%; CEREGE: $4.2-$ $14.4 \%$ ) and the results lie between those obtained using the iGFD and SWF methods. However, as the calculated results of UWO and WIS are within the pooled standard deviation of all laboratories, the amount of material lost via SWF, the amount of water/-OH groups removed by iGFD and the number of $\mathrm{OH}^{-}$groups exchanged by CIE have no impact on the final $\delta^{18} \mathrm{O}$ value.

Pooled $\delta^{18} \mathrm{O}$ values have been calculated from the laboratories' mean $\delta^{18} \mathrm{O}$ values excluding outliers detected by the Grubbs' Test. The $\delta^{18} \mathrm{O}$ values for the two diatom working standards are $+42.8 \% \pm 0.8 \%$ for PS1772-8 and $+29.0 \% \pm 0.3 \%$ for $\mathrm{BFC}$, respectively. Both results are similar within error to values published earlier (PS17728 : $+43.3 \pm 0.3 \%$; BFC: $+28.9 \pm 0.3 \%$ ) (Chapligin et al., 2010). The two phytolith working standards have pooled $\delta^{18} \mathrm{O}$ values of $+37.0 \pm 0.8 \%$ for MSG60 and $+36.6 \pm 0.8 \%$ for G95-25-CL leaves, which are also within error of the previously published results (MSG60: $\delta^{18} \mathrm{O}=+38.4 \pm 0.5 \%$, corrected $\delta^{18} \mathrm{O}=+37.4 \%$, cf. Correction for CEREGE values; G95: $\delta^{18} \mathrm{O}=+36.3 \%$ ) (Webb and Longstaffe, 2002; Crespin et al., 2008). The pooled mean value of the synthetically-produced working standard NFC was $+27.0 \pm 0.3 \%$. It had not been analysed previously. The crystalline working standard HT has a $\delta^{18} \mathrm{O}$ value of $+23.2 \pm 0.9 \%$. This is significantly different from the published value of $25.6 \pm 0.2 \%$ (Lücke et al., 2005) and testifies the usefulness to adopt a new $\delta^{18} \mathrm{O}$ value for E. Rex at FZJ (cf. section Test design and calibration). 
a) Stress $=0.0090$

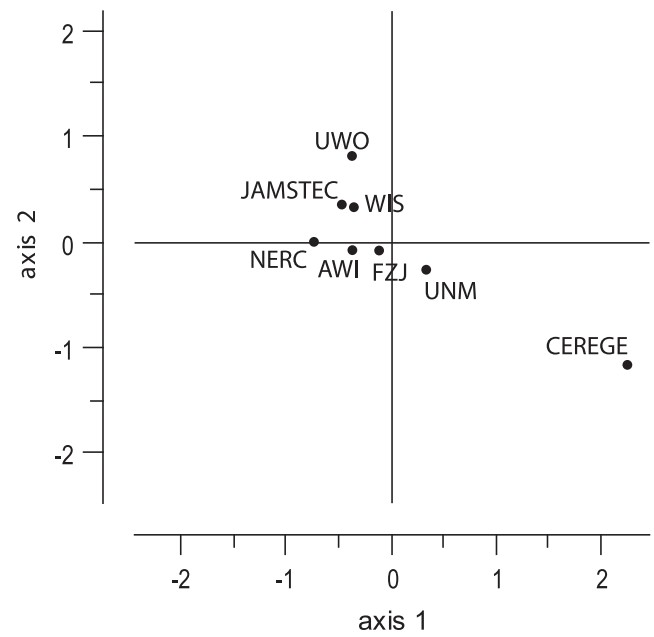

b) Stress $=0.0693$

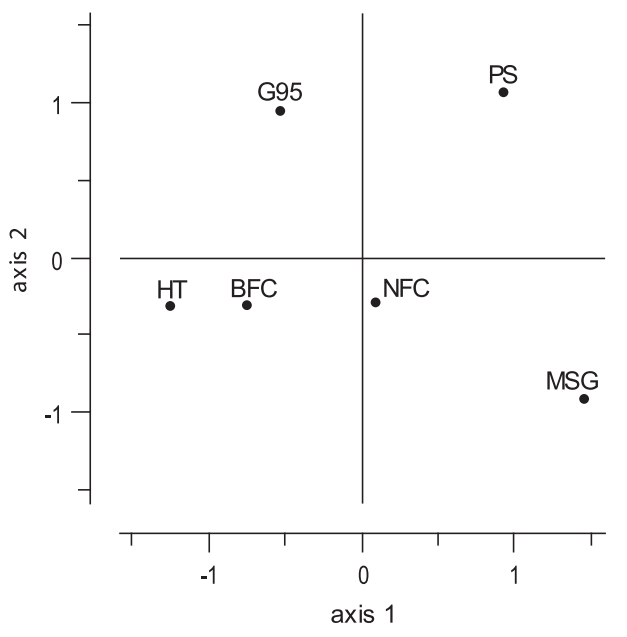

Fig. 4. Biplot of the first two axes of non-metric multidimensional scaling regarding (a) laboratories and (b) working standards.

An overview of the $\delta^{18} \mathrm{O}$ measurements from all laboratories is provided in Fig. 3 and Table 5. Outlying mean $\delta^{18} \mathrm{O}$ values were identified from CEREGE for all values but working standard MSG60, and from UNM for the working standard NFC. UWO obtained a high standard deviation for PS1772-8 and its mean $\delta^{18} \mathrm{O}$ value was also identified as an outlier. The outlier $\delta^{18} \mathrm{O}$ values for NFC (UNM) and PS1771-8 (UWO) and all CEREGE $\delta^{18} \mathrm{O}$ values except MSG60 are not considered further for determining the pooled $\delta^{18} \mathrm{O}$ values and the pooled standard deviation. Correction has been made for outlier $\delta^{18} \mathrm{O}$ values produced by CEREGE (cf. Correction for CEREGE values) and are included in the discussion below. For the scaling analysis (nmMDS) (Fig. 4), the uncorrected values of CEREGE were used to avoid bias and in the UNM data set, the working standard NFC was treated as a missing value.

The standard deviations of single laboratories for mean $\delta^{18} \mathrm{O}$ values lie between $0.1 \%$ and $0.9 \%$ but predominantly range between $0.2 \%$ and $0.3 \%$ (valid for 29 out of 41 mean values, excluding 7 outliers). The pooled standard deviations (all laboratories) of all working standards range between $0.3 \%$ and $0.9 \%(1 \sigma)$ and provide evidence for reasonable agreement among the laboratories and methodologies. For the detection of similarities between the laboratories the nmMDS biplot shows no method related patterns, that is, a low stress value indicates a good representation of the data in two-dimensional space (Fig. 4a). Thus, any differences in $\delta^{18} \mathrm{O}$ values are not methodspecific, but laboratory-specific. Additionally standards of the same material do not form clusters in the working standard-nmMDS biplot (low stress value) indicating that the type of material does not bias analyses results (Fig. 4b). However, the plots need to be interpreted with caution as single values potentially have a strong effect on the models due to the small sample-size of the data-set.

The standard $\delta^{18} \mathrm{O}$ values can be separated into two clusters: those with a lower standard deviation (NFC, BFC: $\mathrm{SD}= \pm 0.3 \%$ ) and those with a higher standard deviation (MSG60, G95, PS1772-8: SD $= \pm 0.8 \%$ ). Excluding the crystalline and impure HT $(\mathrm{SD}=0.9 \%)$, the standard deviation increased for working standards with pooled $\delta^{18} \mathrm{O}$ values further from the reference material used for calibration (NBS28) (pooled $\delta^{18} \mathrm{O}$ value versus pooled standard deviation: $R^{2}=0.76$ ). Apart from FZJ and UWO all laboratories performed a single-point calibration with NBS28 being the only available quartz reference material for $\delta^{18} \mathrm{O}$ measurements only. We recommend that twopoint calibrations should be used preferably including a biogenic standard in the range of the material to be analysed in order to improve inter-laboratory reproducibility.

If successive batches of NFC were to have reproducible $\delta^{18} \mathrm{O}$ values, such synthetic products could have a high potential to be used as a working standard. However, NERC found differences of a few permil between the first and second batches of the working standard NFC precipitated to test this possibility. This suggests that the $\delta^{18} \mathrm{O}$ value of NFC can be batch-specific. This circumstance, together with the potential explosive reaction with $F_{2}$ reagent due to NFC's very hydrous form and small grain size argues against its further use as a working standard.

In summary, we have identified some laboratory-specific differences in the analysis of biogenic silica $\delta^{18} \mathrm{O}$ values, which do not necessarily result from variations among the methods used by the participating laboratories. However, considering the technical differences the observed pooled standard deviation for pooled $\delta^{18} \mathrm{O}$ values lies between 0.3 and $0.9 \%(1 \sigma)$, and reflects a reasonable comparability of this parameter. This difference could be reduced further if two-point calibrations were applied using the standards tested within this inter-laboratory comparison.

\subsection{Correction for CEREGE values}

The mean $\delta^{18} \mathrm{O}$ values for all working standards measured at CEREGE (except MSG 60) were distinguished as outliers from the pooled $\delta^{18} \mathrm{O}$ values. Tests were conducted at CEREGE to examine any possibility of systematic error: before the start of the CIE, the working standards were heated at $350{ }^{\circ} \mathrm{C}$ in order to remove possible labile organic remains that may increase the surface area of the materials; 
the amount of silica subjected to exchange was increased by 6; water-vapour exchange temperature (and associated fractionation factor) was changed; time of vapour-silica exchange was increased while the volume of exchange was reduced by $1 / 3$; the rate of silica dehydration was reduced. None of these tests produced significant changes in the $\delta_{\text {measured }}$ values. The difference between the two labelled waters was reduced by $8 \%$ which did not change the $\delta_{\text {silica }}$ values. Additionally, for two working standards (MSG60, $\mathrm{BFC}$ ), vapour-silica exchanges were carried out at three temperatures $\left(140{ }^{\circ} \mathrm{C}, 200{ }^{\circ} \mathrm{C}\right.$ (usual temperature) and $246^{\circ} \mathrm{C}$ ). Changes in $\delta_{\text {measured }}$ values were the ones expected from the temperature-dependency of the equilibrium fractionation factors.

The methodological bias assumed to occur during vapoursilica exchange, remains unexplained but is however reproducible and can be independently quantified For this purpose, differences were calculated between $\Delta_{\text {vapour-Oexchanged }}$ values obtained at at 140 and $200^{\circ} \mathrm{C}$ for the whole set of working standards (except NFC) and $\Delta_{\text {vapour-Oexchanged }}$ values previously calibrated (at 140 and $200{ }^{\circ} \mathrm{C}$ ) for diatoms (Labeyrie and Juillet, 1982). These values ( $\Delta_{\text {vapour-Oexchanged @ CEREGE }}-\Delta_{\text {vapour-Oexchanged from Labeyrie }}$ and Juillet (1982) were invariant with temperature and did not show any relationship with the measured percentage of exchangeable oxygen $\left(R^{2}=0.08\right)$ but decreased with increasing $\delta^{18} \mathrm{O}_{\text {silica }}$ values ( $R^{2}=0.4$ and 0.9 after outlier removal), which reflects the increasing difference between $\delta_{\text {silica }}$ values and the biased $\delta_{\text {Oexchanged }}$ values produced at CEREGE. In a first step, the empirical relationship was used to correct the values of $\Delta_{\text {vapour-Oexchanged @ CEREGE }}$ as follows:

$$
\text { Corrected } \Delta_{1}=\Delta_{2}-1.3^{*} \delta_{18} \mathrm{O}_{\mathrm{x}}+78
$$

with:

$1=$ vapour-Oexchanged at CEREGE

$2=$ vapour-Oexchanged from Labeyrie and Juillet (1982)

$\mathrm{x}=$ silica at CEREGE

In a second step, the corrected $\Delta_{\text {vapour-Oexchanged values }}$ were used to correct the $\delta^{18} \mathrm{O}_{\text {silica }}$ values. Differences between corrected $\delta^{18} \mathrm{O}_{\text {silica }}$ values and the pooled values range from $-0.1 \%$ MSG60) to $+2.9 \%$ (G95) (Table 5, CEREGE corr). The consistency of this correction was verified using an independent data set previously obtained at CEREGE for fresh water diatoms (Crespin et al., 2010).

\section{CONCLUSIONS}

An inter-laboratory comparison for the $\delta^{18} \mathrm{O}$ values of biogenic silica was conducted to validate analytical protocols used at different laboratories and to develop new biogenic working standards. Six potential working standards (PS1778-2, BFC, MSG60, G95-25-CL leaves, HT, NFC) were analysed by eight laboratories (AWI, NERC, UNM, UWO, WIS, CEREGE, FZJ, JAMSTEC) using four different methods to compensate for exchangeable oxygen (CIE, SWF, iHTR, iGFD) (Table 1). Four of the proposed working standards have $\mathrm{SiO}_{2}$ contents of $>97 \%$, as determined using XRF and an amorphous $\mathrm{SiO}_{2}$ structure verified by XRD analysis. The pooled $\delta^{18} \mathrm{O}$ values calculated from the laboratories' mean values for the two diatom working standards are $+42.8 \%$ for PS $1772-8$ and $+29.0 \%$ for BFC, respectively. The two phytolith working standards have pooled $\delta^{18} \mathrm{O}$ values of $+37.0 \%$ or MSG60 and $+36.6 \%$ for G95-25-CL leaves. Despite the different analytical methods utilized, the overall precision for all working standards lies between $0.3 \%$ and $0.9 \%$ o $(1 \sigma)$ while the internal reproducibility for individual laboratories ranges predominantly between $0.2 \%$ and $0.3 \%$. We suggest that these four materials (PS1772-8, BFC, MSG60, G95-25-CL-leaves) are suitable for use as oxygen-isotope working standards for biogenic silica. The proposed working standards are available from the respective laboratory which supplied the material.

The mean $\delta^{18} \mathrm{O}$ values obtained by one CIE laboratory (CEREGE), except for one working standard, were all outliers, and a methodological correction for this bias has been proposed. The results from one iHTR laboratory (JAMSTEC) showed a higher standard deviation when a two-point calibration was not utilized. Small differences in $\delta^{18} \mathrm{O}$ values (mean $\mathrm{SD}=0.5 \%$, excluding outliers) existed between the laboratories applying SWF.

Notwithstanding these variations, the mean SDs of the mean $\delta^{18} \mathrm{O}$ values from each cluster of laboratories applying the same method were only slightly lower than the overall mean SD from the pooled values. This indicates that laboratory-specific variations are greater than any methodological ones. Future oxygen-isotope analyses of biogenic opal should be calibrated using a two-point calibration that includes NBS28 and one of the proposed new working standards with a $\delta^{18} \mathrm{O}$ value closest to the sample. This approach should further decrease any laboratory bias. Future studies of oxygen isotopes in biogenic silica should state the biogenic working standard used (type of silica, $\delta^{18} \mathrm{O}$ value and analytical precision). This will improve international standardization in the reporting of $\delta^{18} \mathrm{O}$ values of biogenic silica.

\section{ACKNOWLEDGEMENTS}

This work was part of a Ph.D. research project funded by the German Research Foundation with the research grants DFG Me 3266-1-1 and 3266-1-2. We would like to express our sincere gratitude to all technical staff and laboratory assistants involved in the analyses including Kim Law and Lisa Munro (UWO), Irena Brailovski (WIS) and Franz Leistner (FZJ), Lutz Schoenicke and Cindy Springer (AWI). In addition, we thank Helga Kemnitz and Rudolph Naumann from the German Research Center for Geosciences for their SEM and XRD support, respectively. Funding for GEAS was provided by a NERC postdoctoral fellowship award (NE/F012969/1). The research contributions of EAW and FJL were supported by the Natural Sciences and Engineering Research Council of Canada.

\section{REFERENCES}

Bertermann R., Kröger N. and Tacke R. (2003) Solid-state ${ }^{29} \mathrm{Si}$ MAS NMR studies of diatoms: structural characterization of biosilica deposits. Anal. Bioanal. Chem. 375, 630-634.

Borthwick J. and Harmon R. S. (1982) A note regarding $\mathrm{CIF}_{3}$ as an alternative to $\mathrm{BrF}_{5}$ for oxygen isotope analysis. Geochim. Cosmochim. Acta 46, 1665-1668. 
Brandriss M. E., O’Neil J. R., Edlund M. B. and Stoermer E. F. (1998) Oxygen isotope fractionation between diatomaceous silica and water. Geochim. Cosmochim. Acta 62, 1119-1125.

Brewer T. S., Leng M. J., Mackay A. W., Lamb A. L., Tyler J. J. and Marsh N. G. (2008) Unravelling contamination signals in biogenic silica oxygen isotope composition; the role of major and trace element geochemistry. J. Quat. Sci. 23, 321-330.

Chapligin B., Meyer H., Friedrichsen H., Marent A., Sohns E. and Hubberten H. W. (2010) A high-performance, safer and semiautomated approach for the $\delta^{18} \mathrm{O}$ analysis of diatom silica and new methods for removing exchangeable oxygen. Rapid Commun. Mass Spectrom. 24, 2655-2664.

Clarke K. R. and Ainsworth M. (1993) A method of linking multivariate community structure to environmental variables. Mar. Ecol. Prog. Ser. 92, 205-219.

Conley D. J. (1998) An interlaboratory comparison for the measurement of biogenic silica in sediments. Mar. Chem. 63, 39-48.

Crespin J., Alexandre A., Sylvestre F., Sonzogni C., Paillès C. and Garreta V. (2008) IR laser extraction technique applied to oxygen isotope analysis of small biogenic silica samples. Anal. Chem. 80, 2372-2378.

Crespin J., Sylvestre F., Alexandre A., Sonzogni C., Paillès C. and Perga M.-E. (2010) Re-examination of the temperature-dependent relationship between $\delta^{18} \mathrm{O}_{\text {diatoms }}$ and $\delta^{18} \mathrm{O}_{\text {lake water }}$ and implications for paleoclimate inferences. J. Paleolimnol. 44, $547-557$.

Dodd J. P. and Sharp Z. D. (2010) A laser fluorination method for oxygen isotope analysis of biogenic silica and a new oxygen isotope calibration of modern diatoms in freshwater environments. Geochim. Cosmochim. Acta 74, 1381-1390.

Ellwood M. J. and Hunter K. A. (1999) Determination of the $\mathrm{Zn} / \mathrm{Si}$ ratio in diatom opal: a method for the separation, cleaning and dissolution of diatoms. Mar. Chem. 66, 149-160.

Garlick G. D. and Epstein S. (1967) Oxygen isotope ratios in coexisting minerals of regionally metamorphosed rocks. Geochim. Cosmochim. Acta 31, 181-214.

Gersonde R. and Hempel G. (1990) Die Expeditionen ANTARKTIS-VIII/3 und VIII/4 mit FS Polarstern 1989. Rep. Pol. Res.. Alfred Wegener Institute for Polar and Marine Research, Bremerhaven.

Gröning M., Dargie M. and Winckler G. (2007) Reference Sheet for Reference Materials. International Atomic Energy Agency (IAEA), Vienna.

Haimson M. and Knauth L. P. (1983) Stepwise fluorination - a useful approach for the isotopic analysis of hydrous minerals. Geochim. Cosmochim. Acta 47, 1589-1595.

Hodson M. J., Parker A. G., Leng M. J. and Sloane H. J. (2008) Silicon, oxygen and carbon isotope composition of wheat (Triticum aestivum L.) phytoliths: implications for palaeoecology and archaeology. J. Quat. Sci. 23, 331-339.

Hut G. (1987) Stable isotope reference samples for geochemical and hydrological investigations. Rep. Consultants Group Meeting International Atomic Energy Agency, Vienna 1985.

Jones J. B., Sanders J. V. and Segnit E. R. (1964) Structure of Opal. Nature 204, 990-991.

Juillet-Leclerc A. and Labeyrie L. (1987) Temperature dependence of the oxygen isotopic fractionation between diatom silica and water. Earth Planet. Sci. Lett. 84, 69-74.

Kawabe I. (1978) Calculation of oxygen isotope fractionation in quartz-water system with special reference to the low temperature fractionation. Geochim. Cosmochim. Acta 42, 613-621.

Knauth L. P. and Epstein S. (1982) The nature of water in hydrous silica. Am. Mineral. 67, 510-520.

Kruskal J. B. (1964) Nonmetric multidimensional scaling: a numerical method. Psychometrika 29, 115-129.
Labeyrie L. D. and Juillet A. (1982) Oxygen isotopic exchangeability of diatom valve silica; interpretation and consequences for paleoclimatic studies. Geochim. Cosmochim. Acta 46, 967975.

Labeyrie L. J. (1974) New approach to surface seawater paleotemperatures using ${ }^{18} \mathrm{O} /{ }^{16} \mathrm{O}$ ratios in silica of diatom frustules. Nature 248, 40-42.

Lamb A. L., Brewer T. S., Leng M. J., Sloane H. J. and Lamb H. F. (2007) A geochemical method for removing the effect of tephra on lake diatom oxygen isotope records. J. Paleolimnol. 37, 499-516.

Leng M., Barker P., Greenwood P., Roberts N. and Reed J. (2001) Oxygen isotope analysis of diatom silica and authigenic calcite from Lake Pinarbasi, Turkey. J. Paleolimnol. 25, 343-349.

Leng M., Swann G. E. A., Hodson M. J., Tyler J. J., Patwardhan S. W. and Sloane H. J. (2009) The potential use of silicon isotope composition of biogenic silica as a proxy for environmental change. Silicon 1, 65-77.

Leng M. J. and Barker P. A. (2006) A review of the oxygen isotope composition of lacustrine diatom silica for palaeoclimate reconstruction. Earth-Sci. Rev. 75, 5-27.

Leng M. J. and Marshall J. D. (2004) Palaeoclimate interpretation of stable isotope data from lake sediment archives. Quat. Sci. Rev. 23, 811-831.

Leng M. J. and Sloane H. J. (2008) Combined oxygen and silicon isotope analysis of biogenic silica. J. Quat. Sci. 23, 313-319.

Lücke A., Moschen R. and Schleser G. H. (2005) High-temperature carbon reduction of silica: a novel approach for oxygen isotope analysis of biogenic opal. Geochim. Cosmochim. Acta 69, 1423-1433.

Mackay A. W., Karabanov E., Leng M. J., Sloane H. J., Morley D., Panizzo V. N., Khursevich G. and Williams D. (2008) Reconstructing hydrological variability in Lake Baikal during MIS 11; an application of oxygen isotope analysis of diatom silica. J. Quat. Sci. 23, 365-374.

Matheney R. K. and Knauth L. P. (1989) Oxygen-isotope fractionation between marine biogenic silica and seawater. Geochim. Cosmochim. Acta 53, 3207-3214.

Mattey D. and Macpherson C. (1993) High-precision oxygen isotope microanalysis of ferromagnesian minerals by laserfluorination. Chem. Geol. 105, 305-318.

Mikkelsen N., Labeyrie L. and Berger W. H. (1978) Silica oxygen isotopes in diatoms: a 20,000 yr record in deep-sea sediments. Nature 271, 536-538.

Mopper K. and Garlick G. D. (1971) Oxygen isotope fractionation between biogenic silica and ocean water. Geochim. Cosmochim. Acta 35, 1185-1187.

Morley D. W., Leng M. J., Mackay A. W., Sloane H. J., Rioual P. and Battarbee R. W. (2004) Cleaning of lake sediment samples for diatom oxygen isotope analysis. J. Paleolimnol. 31, 391-401.

Moschen R., Lücke A., Parplies J., Radtke U. and Schleser G. H. (2006) Transfer and early diagenesis of biogenic silica oxygen isotope signals during settling and sedimentation of diatoms in a temperate freshwater lake (Lake Holzmaar, Germany). Geochim. Cosmochim. Acta 70, 4367-4379.

Reynolds B. C., Aggarwal J., Andrè L., Baxter D., Beucher C., Brzezinski M. A., Engström E., Georg B. R., Land M., Leng M. J., Opfergelt S., Rodushkin I., Sloane H. I., van der Boorn S. H. J. M., Vroon P. Z. and Cardinal D. (2007) An interlaboratory comparison of $\mathrm{Si}$ isotope reference materials. $J$. Anal. At. Spectrom. 22, 561-568.

Rice S. B., Freund H., Huang W.-L., Clouse J. A. and Isaacs C. M. (1995) Application of Fourier transform infrared spectroscopy to silica diagenesis: the opal-A to opal-CT transformation. $J$. Sedimentary Res. A65, 639-647. 
Rings A., Lücke A. and Schleser G. H. (2004) A new method for the quantitative separation of diatom frustules from lake sediments. Limnol. Oceanogr.: Methods 2, 25-34.

Rosqvist G. C., Rietti-Shati M. and Shemesh A. (1999) Late glacial to middle Holocene climatic record of lacustrine biogenic silica oxygen isotopes from a Southern Ocean island. Geology 27, 967-970.

Schmidt M., Botz R., Stoffers P., Anders T. and Bohrmann G. (1997) Oxygen isotopes in marine diatoms: a comparative study of analytical techniques and new results on the isotope composition of recent marine diatoms. Geochim. Cosmochim. Acta 61, 2275-2280.

Shahack-Gross R., Shemesh A., Yakir D. and Weiner S. (1996) Oxygen isotopic composition of opaline phytoliths: potential for terrestrial climatic reconstruction. Geochim. Cosmochim. Acta 60, 3949-3953.

Sharp Z. D. (1990) A laser-based microanalytical method for the in situ determination of oxygen isotope ratios of silicates and oxides. Geochim. Cosmochim. Acta 54, 1353-1357.

Sharp Z. D. (1992) In situ laser microprobe techniques for stable isotope analysis. Chem. Geol. 101, 3-19.

Shemesh A., Burckle L. H. and Hays J. D. (1995) Late Pleistocene oxygen isotope records of biogenic silica from the Atlantic sector of the Southern Ocean. Paleoceanography 10, 179-196.

Shemesh A., Charles C. D. and Fairbanks R. G. (1992) Oxygen isotopes in biogenic silica: global changes in ocean temperature and isotopic composition. Science 256, 1434-1436.

Shemesh A., Mortlock R. A., Smith R. J. and Froelich P. N. (1988) Determination of $\mathrm{Ge} / \mathrm{Si}$ in marine siliceous microfossils: separation, cleaning and dissolution of diatoms and radiolaria. Mar. Chem. 25, 305-323.

Shemesh A. and Peteet D. (1998) Oxygen isotopes in fresh water biogenic opal- Northeastern US Alleröd-Younger Dryas temperature shift. Geophys. Res. Lett. 25, 1935-1938.

Shemesh A., Rosqvist G., Rietti-Shati M., Rubensdotter L., Bigler C., Yam R. and Karlén W. (2001) Holocene climatic change in
Swedish Lapland inferred from an oxygen-isotope record of lacustrine biogenic silica. Holocene 11, 447-454.

Stoeber W., Fink A. and Bohn E. (1968) Controlled Growth of monodisperse silica spheres in the micron size range. $J$. Colloid Interface Sci. 26, 62-69.

Swann G. E. A. and Leng M. J. (2009) A review of diatom $\delta^{18} \mathrm{O}$ in palaeoceanography. Quat. Sci. Rev. 28, 384-398.

Swann G. E. A., Leng M. J., Sloane H. J. and Maslin M. A. (2008) Isotope offsets in marine diatom delta (super 18) O over the last 200 ka. J. Quat. Sci. 23, 389-400.

Swann G. E. A., Maslin M. A., Leng M. J., Sloane H. J. and Haug G. H. (2006) Diatom $\delta^{18} \mathrm{O}$ evidence for the development of modern halocline system in the subarctic northwest pacific at the onset of major Northern Hemisphere glaciation. Paleoceanography 21, PA1009.

Swann G. E. A. and Patwardhan S. V. (2011) Application of Fourier transform infrared spectroscopy (FTIR) for assessing biogenic silica sample purity in geochemical analyses and palaeoenvironmental research. Clim. Past 7, 65-74.

Tyler J. J., Leng M. J., Sloane H. J., Sachse D. and Gleixner G. (2008) Oxygen isotope ratios of sedimentary biogenic silica reflect the European transcontinental climate gradient. J. Quat. Sci. 23, 341-350.

Vennemann T. W., Eckert C. and Hubberten H. W. (2002) Laserbased oxygen isotope analysis of biogenic silica. 12th Annual Goldschmidt Conference 2002. Suppl. Geochim. Cosmochim. Acta 66, 804.

Webb E. A. and Longstaffe F. J. (2002) Climatic influences on the oxygen isotopic composition of biogenic silica in prairie grass. Geochim. Cosmochim. Acta 66, 1891-1904.

Webb E. A. and Longstaffe F. J. (2000) The oxygen isotopic compositions of silica phytoliths and plant water in grasses: implications for the study of paleoclimate. Geochim. Cosmochim. Acta 64, 767-780. 